\title{
Competitividad entre metrópolis de América Latina*
}

\section{NELSON MANZANO**}
** Economista, investigador del Instituto de Estudios Sociales y Económicos (IESE) de la Universidad Mayor de San Simón (UMSS) de Cochabamba - Bolivia.

\begin{abstract}
The performance of urban economic structures can be analyzed in different ways and from different methodological perspectives. Nevertheless, it is imperative to undertake an initial overview in terms of comparative dynamics over time. Based on this, the research provides an approach to the issue over the period 2001-2008, applying the paradigm of urban competitiveness, to analyze a selection of indicators of urban competitiveness (city rankings). This process is complemented by an exercise that identifies some of the key factors that influence the current performance and regional positioning of a representative sample of metropolitan economies in Latin America.
\end{abstract}

KEY WORDS: Latin America, metropolitan areas, urban competitiveness, quality of life.

RESUMEN El desempeño de las estructuras económicas urbanas puede ser analizado de distintas maneras y a partir de diversos enfoques metodológicos. No obstante, se considera esencial la realización de un abordaje inicial en torno a sus dinámicas comparadas a lo largo de un periodo de tiempo. En este marco, la presente investigación constituye un acercamiento a la temática durante el periodo 2001-2008, aplicando el paradigma de competitividad urbana, para analizar un conjunto selecto de indicadores de niveles de competitividad urbana (ranking de ciudades). Este proceso será complementado con un ejercicio de identificación de algunos de los factores esenciales que estarían influenciando el actual desempeño y posicionamiento regional de una muestra representativa de 21 economías metropolitanas de América Latina.

PALABRAS CLAVE: América Latina, áreas metropolitanas, competitividad urbana, calidad de vida.

\footnotetext{
* Resumen de la ponencia presentada en el VI Foro Internacional sobre Competitividad Urbana (Ciudad de México el 20 y 21 de noviembre de 2008).

Recibido el 17 de marzo de 2008, aprobado el 31 de agosto de 2009.

Correspondencia: Email: nmanzano@iese.umss.edu.bo
} 


\section{Introducción}

La naturaleza de los centros urbanos, así como sus dinámicas e importancia, han sido, desde tiempos antiguos, fenómenos que llamaron la atención de diversas ciencias y enfoques disciplinarios. No obstante, desde el punto de vista estrictamente económico, las ciudades adquieren relevancia investigativa, a partir de la constatación de la conexión analítica entre los procesos de urbanización -es decir, la concentración espacial de las actividades humanas-y los procesos de crecimiento económico y desarrollo generados en sus respectivos entornos territoriales. Por ello, el estudio de las ciudades -en tanto objeto de investigación- permite un acercamiento teórico e instrumental respecto al desempeño general, no solo de las economías locales, sino también de las economías nacionales, sub-regionales y continentales de las que forman parte.

Cabe aclarar, sin embargo, que debido a que la importancia y alcance investigativo de las ciudades trasciende, con mucho, el ámbito estrictamente económico, el enfoque analítico que se utilizará prioriza la utilización del paradigma de la competitividad urbana, dada su particular cualidad analítica integradora en el estudio de las dinámicas urbanas y sus interrelaciones con otras ramas disciplinarias como la economía espacial, la geografía económica, la economía ambiental y la economía institucional, entre otras. El desafío fundamental de la presente investigación es -por lo tanto- realizar una aproximación teórico-conceptual, pero principalmente descriptiva, en torno al tema de la competitividad metropolitana en América Latina, a partir de un abordaje metodológico que priorice su componente económico.

No obstante, la presente propuesta analítica enfrenta un conjunto de restricciones metodológicas donde resaltan dos principales: una primera de carácter espacial, referida a la escasa información económica disponible para ciudades; y una segunda de carácter temático, asociada a la todavía débil importancia que aún se le asigna a la agenda urbana en los ámbitos público y privado de la sociedad latinoamericana y que redunda en una también débil presencia de trabajos descriptivo-analíticos especializados.

\section{Importancia de la economía latinoamericana y sus principales metrópolis}

El tamaño y la importancia de las economías latinoamericanas a inicios del siglo veintiuno pueden medirse mediante su participación en tres principales rubros, a saber: la producción (Producto Interno Bruto, PIB), el flujo de Inversión Extranjera Directa (IED) que atraen, y su comercio exterior, medido por el valor de sus exportaciones de bienes y servicios. De acuerdo a la información del Cuadro 1, en 2007 el PIB generado por América Latina fue de \$US 3.620.748 mill., que representó el 6,2\% del PIB mundial en términos nominales, y el 8,3\% según paridad de poder adquisitivo del dólar. Sin embargo, en 1995 había representado un $8,8 \%$, mostrandose así una relativa pérdida de participación de la economía regional a nivel mundial durante la última década, debido a la existencia de eventuales periodos de recesión, pero principalmente debido a las relativamente bajas tasas de crecimiento en comparación a las registradas por otras regiones del mundo. En este marco, la composición del PIB de América Latina muestra que en 2007 las cinco mayores economías nacionales (Brasil, México, Venezuela, Colombia y Argentina) aportaron un 83\% del PIB latinoamericano, y las dos primeras el 63\% (Brasil, 35\% y México, 28\%), evidenciando la alta concentración de 
la producción y de la productividad, pues estas economías desplegaron PIB per cápita (PIB pc) superiores al promedio regional (US\$ 4.915), donde destacan los casos de Chile (US\$ 8.873), México (US\$ 7.975), Venezuela (US\$ 6.734) y Brasil (US\$ 5.516). Las excepciones lo constituyen Colombia, Uruguay, Costa Rica y Puerto Rico, la primera debido a que aun cuando tiene una importante economía nacional, su PIB pc es inferior al promedio; y las tres siguientes, debido a que siendo pequeńas economías nacionales tienen un PIB pc superior al promedio regional. Un caso especial de mencionar es el referido al PIB pc de Puerto Rico (el mayor de América Latina en 2007, US\$13.300 en valor corriente) que, no obstante, debe ser relativizado debido a su especial relación político-administrativa con los EE.UU., a partir de la cual las personas nacidas en este país caribeño tienen ciudadanía norteamericana (Acta Jones de 1917).

CUADRO 1. PIB, INVERSIÓN EXTRANJERA DIRECTA Y EXPORTACIONES EN AMÉRICA LATINA

\begin{tabular}{|c|c|c|c|c|c|c|c|}
\hline $\begin{array}{l}\text { Paises de } \\
\text { América Latina }\end{array}$ & $\begin{array}{c}\text { PIB } \\
\text { total }(2007)^{1}\end{array}$ & $\begin{array}{l}\text { Participación del } \\
\text { PIB a nivel } \\
\text { latinoamericano }\end{array}$ & $\begin{array}{l}\text { PIB per cápita } \\
(2006)^{2}\end{array}$ & IED $(2007)^{1}$ & $\begin{array}{l}\text { Participación del } \\
\text { IED a nivel } \\
\text { latinoamericano }\end{array}$ & $\begin{array}{c}\text { Exportaciones } \\
(2006)^{1}\end{array}$ & $\begin{array}{c}\text { Participación } \\
\text { de las expor- } \\
\text { taciones a nivel } \\
\text { latinoamericano }\end{array}$ \\
\hline Argentina & 262.327 & 7,2 & 5.498 & 5.720 & 4,9 & 53.051 & 7,2 \\
\hline Chile & 163.915 & 4,5 & 8.873 & 14.457 & 12,5 & 66.246 & 8,9 \\
\hline México & 1.022 .063 & 28,2 & 7.975 & 23.230 & 20,0 & 267.947 & 36,1 \\
\hline Colombia & 202.925 & 5,6 & 3.220 & 9.028 & 7,8 & 24.972 & 3,4 \\
\hline Perú & 107.054 & 3,0 & 3.351 & 5.343 & 4,6 & 26.340 & 3,6 \\
\hline Brasil & 1.268 .460 & 35,0 & 5.616 & 34.585 & 29,8 & 156.486 & 21,1 \\
\hline Ecuador & 43.085 & 1,2 & 3.088 & 179 & 0,2 & 14.192 & 1,9 \\
\hline Uruguay & 23.087 & 0,6 & 5.808 & 879 & 0,8 & 5.764 & 0,8 \\
\hline Puerto Rico & 90.359 & 2,5 & 13.300 & n.d. & n.d. & n.d. & n.d. \\
\hline República Dominicana & 41.013 & 1,1 & 3.711 & 1.698 & 1,5 & 10.695 & 1,4 \\
\hline Paraguay & 11.954 & 0,3 & 1.500 & 142 & 0,1 & 5.274 & 0,7 \\
\hline Venezuela & 228.071 & 6,3 & 6.734 & 646 & 0,6 & 66.610 & 9,0 \\
\hline Guatemala & 33.432 & 0,9 & 2.353 & 536 & 0,5 & 7.729 & 1,0 \\
\hline Costa Rica & 26.230 & 0,7 & 5.053 & 1.889 & 1,6 & 11.031 & 1,5 \\
\hline Bolivia & 13.120 & 0,4 & 1.159 & 164 & 0,1 & 4.743 & 0,6 \\
\hline Total America Latina ${ }^{3}$ & 3.619 .748 & 100,0 & 4.915 & 116.009 & 100,0 & 741.447 & 100,0 \\
\hline
\end{tabular}

Respecto a la capacidad de atracción de recursos de inversión extranjeros, las economías latinoamericanas que más se destacan son las de Brasil, México, Chile y Colombia, que juntas absorbieron en 2006 el 70\% del total de flujos de IED de América Latina, particularmente las tres primeras en las que se localizó el 62,3\% del total de IED (Brasil absorbió el 30\% del total). Llama la atención, sin embargo, la importante localización de IED en economías relativamente pequeñas pero con alto dinamismo como Chile, Colombia y Perú que absorbieron el 12,5; 7,8 y 4,6\% respectivamente del total de la IED que fluyó a Latinoamérica en 2007 y que los posiciona como las economías de mayor potencial de crecimiento en el mediano plazo. De todos modos, es importante mencionar que los citados US\$116.009 mill. de IED del 2007 solo representaron a nivel mundial el 6,5\%, aunque lo que más preocupa -al igual que en el caso del PIB regional- es su tendencia a la baja, pues en 2000 estos flujos representaron el $8,3 \%$ del total mundial. Esta situación no se debería a la disminución absoluta de recursos, sino a la visible mayor dinámica de atracción de capitales extranjeros de otras regiones del mundo, principalmente las economías del sudeste asiático (China e India). No obstante, la proporción de IED dirigida a los sectores de servicios y manufacturas fue mayoritaria (35 y 
$27 \%$, respectivamente), lo que muestra la previsible alta - pero sobre todo creciente- presencia de este tipo de inversiones en las economías urbanas latinoamericanas (CEPAL, 2008).

El comportamiento de las exportaciones regionales, por su parte, estuvo marcado por una presencia importante de México, Brasil, Venezuela, Chile y Argentina, que en 2006 representaron el 82,3\% del total de exportaciones de América Latina y, según la Conferencia de las Naciones Unidas sobre Comercio y Desarrollo (UNCTAD), el 5,1\% del total mundial con un crecimiento del 5,7\% respecto al ańo anterior. Debe anotarse, sin embargo, que la mayor parte del incremento de las exportaciones regionales está referido a productos agrícolas, minerales y manufacturas basadas en materias primas, debido al incremento de los precios internacionales de los comodities (CEPAL, 2006). Este fenómeno es verificado por la Organización Mundial del Comercio (OMC), cuyos registros muestran que las exportaciones latinoamericanas de servicios en 2007 representaron tan solo el 3,3\% del total de exportaciones mundiales de este segmento de comercio, en tanto que las de productos básicos representaron el 8\% (CEPAL, 2008). Como dato complementario se puede mencionar que en el periodo 2000-2004 la participación de los productos primarios en las exportaciones totales de América Latina subió del 25 al 29\%, sin tomar en cuenta los productos manufacturados basados en recursos naturales, que incrementaron su participación del 40 al 47\%, sumando un 76\% de participación conjunta (Mulder, 2006).

Como se sabe, en el contexto de las economías nacionales latinoamericanas resalta con notoriedad la participación urbana, dada la urbanización que registró esta región durante las últimas décadas (CEPAL, 2005). Al respecto, la información del Cuadro 2 permite observar que las 21 principales economías metropolitanas de América Latina -referidas en su gran mayoría a las denominadas "zonas metropolitanas", concebidas como el conjunto de municipios cuyos territorios incorporan segmentos de un área metropolitana o conurbación originada alrededor de una ciudad central- generaron en 2007 un PIB conjunto de US\$ 897.220 mill., lo que representa un 25\% del PIB regional. Resaltan los aportes económicos de cinco principales urbes: Ciudad de México, Sao Paulo, Buenos Aires, Río de Janeiro y Santiago de Chile, cuya producción conjunta representó el $72 \%$ del total, es decir aproximadamente tres cuartas partes. Se verifica así la notoria concentración urbana de la producción, principalmente referida a la Ciudad de México, que en 2007 representó el 29,3\% del total de las 19 economías metropolitanas analizadas. Respecto a la importancia de las citadas economías urbanas en sus ámbitos nacionales, se observa que en 2007 las que tuvieron un mayor aporte-mayor al 25 $\%$ - fueron, por orden de importancia: San Juan (49\%), Buenos Aires (38\%), Montevideo (36\%), Santiago (32\%), San José (27\%) y Lima (27\%), que además desplegaron las mayores tasas de crecimiento de los últimos tres años. En este campo, resaltan también las dinámicas mostradas por las economías de Santo Domingo, Caracas, Lima y Bogotá, que aunque no aportaron significativamente en sus respectivas economías nacionales en 2007 tuvieron tasas de crecimiento anual de PIB pc (2004-2007) por encima o cercanas al 10\%. No obstante, es importante mencionar que en los casos de Lima y Bogotá los citados procesos son resultado del mejoramiento en sus estructuras y dinámicas productivas internas, en tanto que en los restantes parecen responder más bien a procesos de transferencia de recursos del nivel nacional al local. 
CUADRO 2. PIB EN PRINCIPALES METRÓPOLIS DE AMÉRICA LATINA

\begin{tabular}{|c|c|c|c|c|c|}
\hline $\begin{array}{l}\text { Metrópolis principales } \\
\text { de Sud yCentroamérica }\end{array}$ & $\begin{array}{l}\text { PIB total } \\
(2007)^{1}\end{array}$ & $\begin{array}{c}\text { Participación } \\
\text { del PIB a nivel } \\
\text { nacional (2007) } \\
\end{array}$ & $\begin{array}{l}\text { PIB per cápita } \\
(2006)^{2}\end{array}$ & $\begin{array}{l}\text { PIB per cápita } \\
(2007)^{2}\end{array}$ & $\begin{array}{c}\text { Crecimiento promedio } \\
\text { anual PIB per cápita } \\
(2004-2007)\end{array}$ \\
\hline Sao Paulo & 177.360 & 14,0 & 6.337 & 5.944 & 13,0 \\
\hline Santiago & 51.796 & 31,6 & 8.475 & 8.162 & 11,9 \\
\hline Ciudad de México & 230.401 & 22,5 & 12.641 & 11.504 & 7,1 \\
\hline Buenos Aires & 100.517 & 38,3 & 7.898 & 8.329 & 13,1 \\
\hline Monterrey & 48.237 & 4,7 & 13.616 & 13.144 & 8,3 \\
\hline Rio de Janeiro & 64.242 & 5,1 & 6.257 & 5.498 & 11,7 \\
\hline Bogota & 23.591 & 11,6 & 4.125 & 3.233 & 8,1 \\
\hline Lima & 26.662 & 26,8 & 3.353 & 3.433 & 9,0 \\
\hline Curitiba & 19.799 & 1.5 & 5.447 & 6.486 & 12,7 \\
\hline Querétaro $^{3}$ & 13.688 & 1,3 & 8.510 & 14.732 & 27,4 \\
\hline Guadalajara & 34.205 & 3.3 & 9.218 & 8.364 & 6,5 \\
\hline Montevideo & 8.340 & 36,1 & 4.252 & 5.817 & 10,8 \\
\hline San Juan & 44.362 & 49,1 & 14.576 & 18.484 & 7,9 \\
\hline San José & 7.155 & 27,3 & 4.752 & 4.462 & 3,4 \\
\hline Caracas & 18.222 & 8,0 & 6.319 & 4.753 & 9,4 \\
\hline Santo Domingo ${ }^{3}$ & 10.862 & 26,5 & 2.682 & 3.657 & 13,5 \\
\hline Quito & 4.284 & 9,9 & 2.272 & 2.692 & 1,9 \\
\hline Asunción & 2.316 & 19,4 & 1.437 & 1.245 & 5,1 \\
\hline Ciudad de Guatemala & 7.838 & 23,4 & 2.730 & 2.539 & 5,5 \\
\hline Santa Cruz de la Sierra & 1.784 & 13,6 & 1.150 & 1.269 & 3,1 \\
\hline $\mathrm{La} \mathrm{Paz}{ }^{4}$ & 1.559 & 11,9 & 961 & 961 & 2,8 \\
\hline
\end{tabular}

En relación al PIB pc urbano, es decir, la productividad urbana, se observa que más de la mitad de todas la ciudades consideradas desplegaron en 2007 valores por encima del promedio regional (US\$ 4.915), donde destacan por orden de importancia: San Juan (US\$18.484), Querétaro (US\$14.732), Monterrey (US\$13.144), Ciudad de México (US\$11.504), Guadalajara (\$US. 8.364), Buenos Aires (US\$ 8.329) y Santiago de Chile (US\$ 8.152). Este panorama permite observar tres principales fenómenos: el primero referido a la visiblemente alta productividad de San Juan, que sin embargo, se debe en gran medida a su anexión política y económica con los EE.UU.; el segundo referido a la fuerte presencia de ciudades mexicanas (cuatro de siete), donde destacan Querétaro y Monterrey; y, finalmente, un tercer fenómeno que tiene relación con la existencia de ciertas ciudades cuyo PIB pc es menor al de su país, como son los casos de Santiago de Chile, Santo Domingo, Río de Janeiro, Asunción, Caracas y La Paz, las dos primeras asociadas a la generación de altos PIB no urbanos (basados en la explotación de minerales y turismo), y las restantes asociadas a la existencia de importantes deseconomías externas urbanas presentadas en forma de delincuencia, corrupción e inseguridad jurídica, entre otras.

\section{La competitividad urbana como paradigma de análisis}

El presente estudio utiliza el concepto de competitividad urbana para efectos de identificar y comparar aquellos rasgos esenciales que estarían estimulando o entorpeciendo la conformación de ambientes urbanos propicios para la atracción de inversiones, generación de empleo 
e incremento de la producción e ingresos urbanos. Para ello, se propone una metodología de análisis a partir del uso de los denominados niveles de competitividad urbana -instrumentalizados mediante la elaboración de un ranking de competitividad urbana-, complementado con un análisis contextual en torno a los principales factores de competitividad, así como un breve ejercicio de caracterización de los procesos internos de creación de dinámicas también conocidos como ventajas competitivas.

Como se sabe, los avances teóricos y metodológicos sobre el tema de competitividad han estado tradicionalmente referidos a la elaboración de estudios a nivel internacional (competitividad entre países), aunque también se han elaborado estudios de carácter sectorial (principalmente competitividad industrial) y regional. Por ello, el rasgo fundamental de estos procesos es sin duda su visiblemente limitada atención al estudio de la competitividad urbana, aun cuando el proceso de creación de capacidades de innovación tendría un carácter eminentemente local (Porter, 1991). La buena noticia es, sin embargo, que las naciones y las ciudades no sólo se distinguen por su escala de análisis espacial, sino también porque son unidades territoriales que compiten por atraer distintas cosas. Por esta razón, Cabrero et al. (2003 y 2007), Sobrino (2003), Lever y Turok (1999) y Lever (1993), entre otros, coinciden en la idea de que las ciudades competitivas son aquellas urbes que crean permanentemente condiciones óptimas, no sólo para atraer inversiones del exterior, sino también, para movilizar recursos que se encuentran al interior de una economía nacional (captando flujos interregionales de capital), para obtener fondos públicos (maximizando el presupuesto local y las transferencias del gobierno central), para atraer mano de obra calificada (instalando universidades y centros de investigación de prestigio y excelencia), para atraer mayores y mejores flujos de turismo (priorizando flujos de turistas de mayor poder adquisitivo), y finalmente, para organizar eventos de jerarquía internacional (creando las condiciones locales para ser continuamente anfitriones de convenciones, ferias internacionales y sedes de juegos deportivos, entre otros). Bajo este espíritu, en lo que va de la última década, se desarrollaron un conjunto importante de estudios sobre competitividad urbana, donde resaltan los trabajos elaborados por Begg (1999), Kresl (1995), Deas y Giordano (2001), Turok (2004), Cho (2006) y Pengfei et al. (2006), para países del mundo desarrollado, en tanto que Sobrino (2003 y 2006), Cabrero et al. (2003 y 2007) y la revista especializada de negocios América Economía, para países y ciudades de América Latina.

En términos conceptuales, la competitividad urbana tiene muchas acepciones, sin embargo, de la literatura revisada destaca la propuesta por Lever y Turok (1999, p. 792), quienes consideran que puede ser entendida como "el grado en que las ciudades producen bienes y servicios que se enfrentan a la prueba de los mercados regional, nacional e internacional, mientras simultáneamente incrementan su ingreso real, mejoran la calidad de vida de sus ciudadanos y promueven el desarrollo de una manera sustentable". Otra aproximación conceptual importante es la proporcionada por Sobrino (2003, p. 145), quien sostiene que "la competitividad urbana alude a la capacidad de una ciudad para insertarse en los mercados nacionales y foráneos y su relación con el crecimiento económico local así como el incremento en la calidad de vida de sus residentes". No obstante, la más reciente definición es la proporcionada por Kresl y Pengfei (2006, p. 48), quienes consideran que la competitividad urbana es "el grado en que una ciudad o región urbana, en comparación con otras ciudades competitivas, es capaz de proveer fuentes de trabajo, ingreso, cultura, amenidades, grado de cohesión social, gobernabilidad y 
medioambiente urbano a los que sus corrientes y nuevos residentes aspiran”. De esta manera, una ciudad sería competitiva sólo si logra crear un círculo virtuoso entre: ampliación de mercados externos (comercio internacional), incrementos en la productividad, incrementos en el ingreso real y, finalmente, mejoras en las condiciones de empleo de la mano de obra y en la calidad de vida de sus habitantes. Es decir, la competitividad se da en tanto una ciudad pueda crear un conjunto específico de capacidades económicas, sociales, institucionales y culturales para que sus territorios urbanos puedan atraer permanentemente inversiones, incentivar las actividades económicas y facilitar su fortalecimiento y desarrollo sostenible, de modo que creen y recreen continuamente las condiciones idóneas para generar riqueza y empleo, que a la postre permitan mejorar la calidad de vida de sus habitantes.

En lo referente a las estimaciones de la competitividad urbana, es importante aclarar que no es lo mismo medir o estimar los niveles de competitividad que sus determinantes -o productos y fuentes (Deas y Giordano, 2001)-, pues los primeros hacen referencia a un conjunto de indicadores tanto cuantitativos como cualitativos que representan medidas de éxito competitivo de una unidad de análisis (ciudad) normalmente ordenados jerárquicamente (ranking); en cambio, los segundos hacen referencia a las variables explicativas de tal desempeño, también conocidas como factores de la competitividad urbana. Dadas las limitaciones de la presente investigación, sus alcances están referidos al análisis de los niveles de competitividad, complementados con algunas aproximaciones a los factores determinantes, a partir de cierta información secundaria, pues siguiendo a Kresl y Singh (1999, p. 1018) "la competitividad no es un atributo que pueda ser medido directamente, por lo que todo lo que uno puede hacer es estimar su naturaleza y magnitud a través de la sombra que va dejando”.

\section{Indicadores de competitividad urbana internacional}

El estado del arte a nivel mundial muestra que existe una relativamente amplia producción de estudios, aproximaciones teóricas y aplicaciones metodológicas referidas a la competitividad urbana, donde destacan las elaboradas por Kresl y Pengfei (2006) para un listado de 110 ciudades de todo el mundo -que incluye a sólo dos metrópolis de América Latina: Buenos Aires y Río de Janeiro-, así como la lista de las denominadas best cities, elaborada anualmente por la consultora internacional Mercer Human Resources and Investment Consulting para 125 ciudades del mundo (Mercer, 2008). Son referentes importantes también el Ranking de las Mejores Ciudades para Hacer Negocios en América Latina, elaborado -también anualmentepor la revista de negocios América Economía para una lista de las 42 principales metrópolis de América Latina, y el Ranking Global de Empresas e Inversión Extranjera Directa, elaborado anualmente por la revista de negocios Fortune.

No obstante, también se evidencia la notoria dificultad para encontrar estudios relativos a la medición específica de niveles de competitividad urbana para ciudades de América Latina, pues sólo la elaborada por la revista América Economía hace referencia a estas urbes. Por ello, y para proceder a un análisis comparativo, en el Cuadro 3 se presenta un resumen de los principales indicadores que utiliza el mencionado ranking de "mejores ciudades para hacer negocios", que si bien no se ajusta totalmente al concepto de competitividad urbana de la presente investigación -debido a que hace referencia a los beneficios y costos relativos que 
orientan las decisiones de atracción de inversión en las grandes urbes latinoamericanas-, permite contar con un panorama general respecto a los desempeńos comparativos anuales de estas economías urbanas.

La metodología utilizada por la revista América Economía selecciona como objeto de estudio a aquellas ciudades de América Latina que tengan más de 500.000 habitantes y que paralelamente adquieran relevancia para los negocios (Figura 1). La medición del citado ranking toma en cuenta el PIB pc ajustado por costo de vida y violencia urbana (Figura 2), además de medir índices compuestos de potencial innovador, competitividad digital (telecomunicaciones), estabilidad política y poder de marca, entre otros. Todo ello a partir de una propuesta metodológica que combina el uso de un conjunto de variables duras obtenidas de fuentes oficiales nacionales (como institutos de estadística, bancos centrales y bolsas de comercio) y de información procesada por organismos internacionales (como el Banco Mundial, el Programa de las Naciones Unidas para el Desarrollo -PNUD- y compañías privadas internacionales como Cisco, BC Richard Ellis, The Heritage Foundation, Cybermetrics y Mercer). Estas fuentes están además apoyadas por información primaria obtenida de una encuesta aplicada a un conjunto selecto de ejecutivos en todo el mundo, que si bien incorpora ciertas limitaciones, permite contar con información especializada que puede eventualmente ser utilizada para realizar análisis comparativos generales, de carácter transversal y temporal. Y es que aun cuando la citada metodología de medición o estimación de variables se modificó en los últimos años, mantuvo para sí las partes esenciales de su estructura, característica que -como veremos posteriormente- se confirma a partir de la constatación de que las tendencias de mejoramiento, debilitamiento o mantenimiento de la competitividad de las principales metrópolis - pero sobre todo de los grupos conformados por las ciudades consideradas más competitivas y menos competitivas- se mantuvieron, con pocas excepciones, relativamente estables durante el periodo analizado.

CUADRO 3. INDICADORES DE COMPETITIVIDAD URBANA INTERNACIONAL (2008)

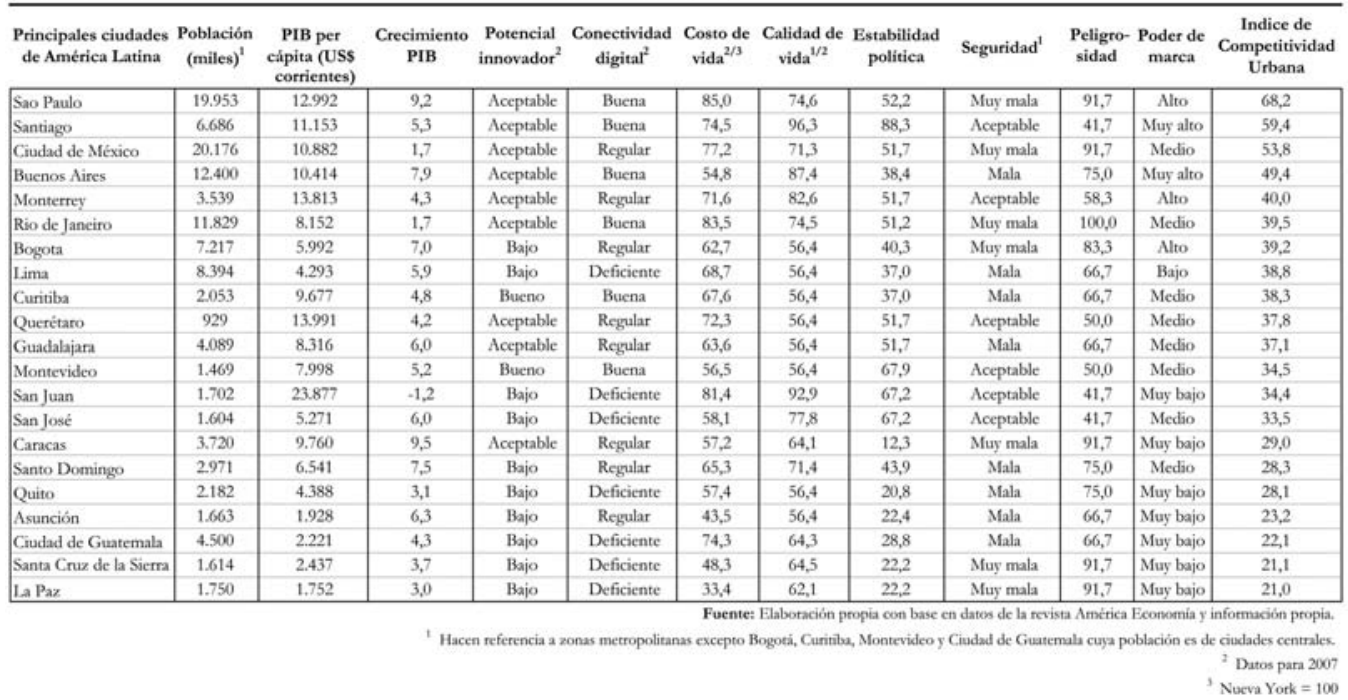


FIGURA 1. POBLACIÓN DE PRINCIPALES METRÓPOLIS DE AMÉRICA LATINA (2008)

Leyenda

Población (miles de personas)

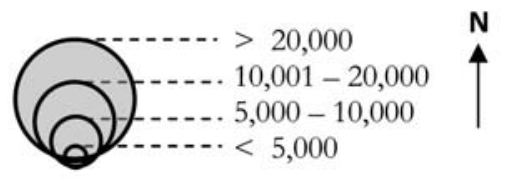

- Metrópolis

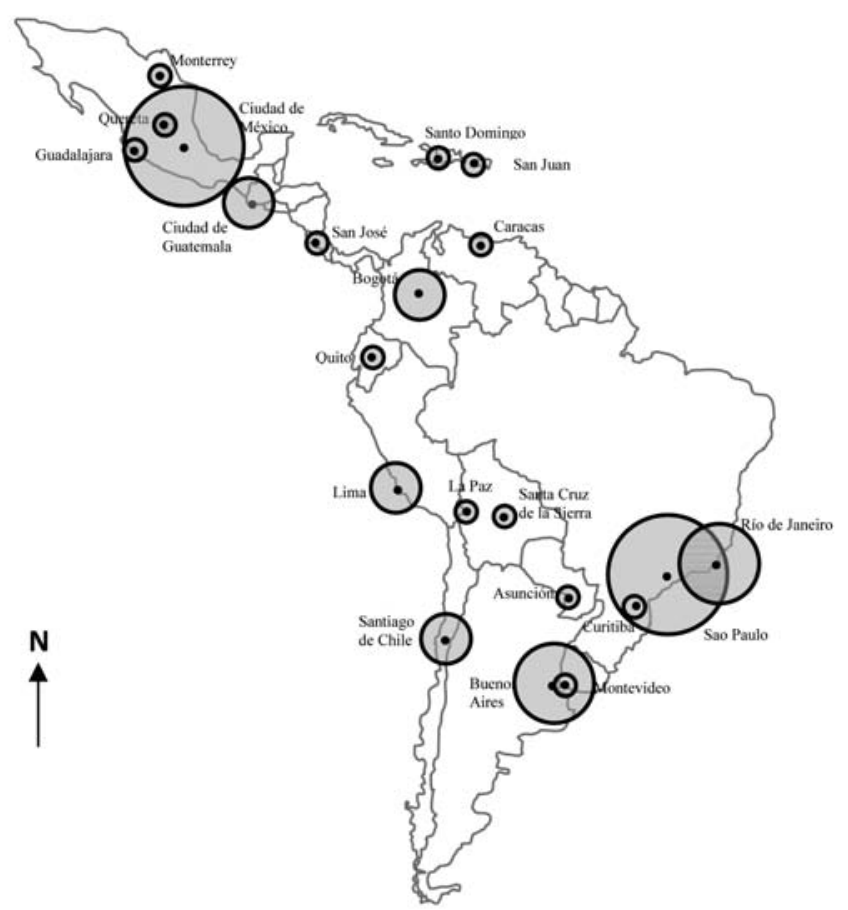

Fuente: Elaboración propia 


\section{FIGURA 2. PIB PC AJUSTADO DE PRINCIPALES METRÓPOLIS DE AMÉRICA} LATINA (2008)

Leyenda PIB pc ajustado (\$US.)

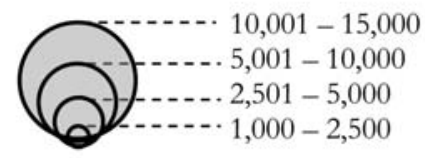

- Metrópolis

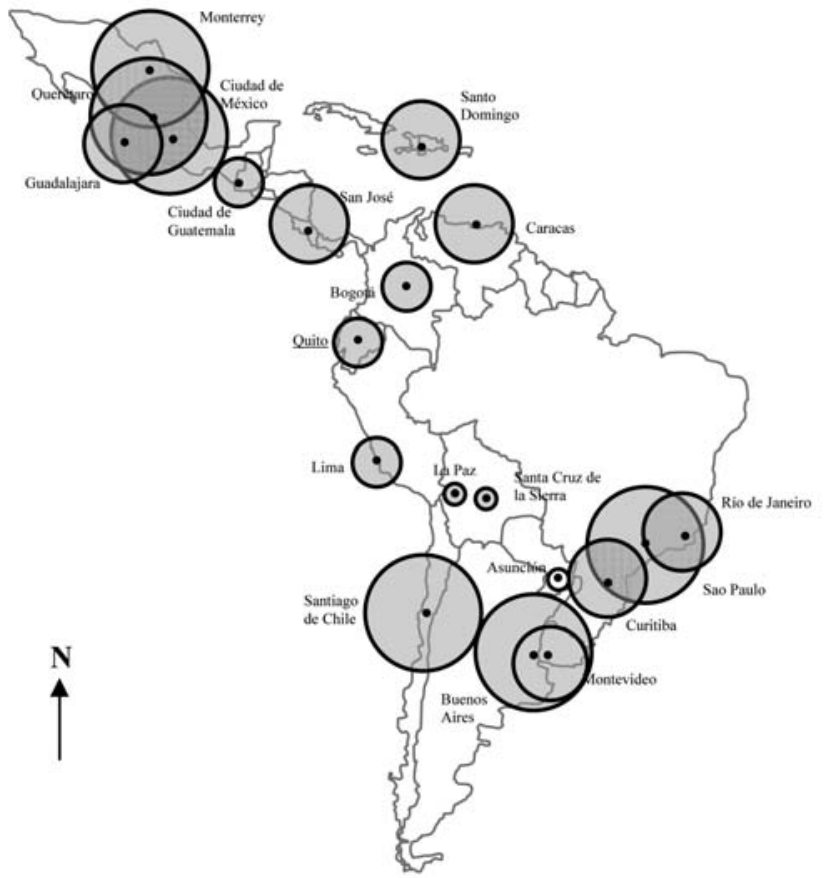

Fuente: Elaboración propia

La información del referido ranking para los años 2001-2008 es presentada en el Cuadro 4, y muestra que las economías metropolitanas de mayor potencial para la atracción de inversiones fueron Sao Paulo, Santiago de Chile, Ciudad de México, Buenos Aires y Monterrey, que se posicionaron en los cinco primeros lugares, aunque Santiago y Monterrey decayeron tres posiciones entre 2007 y 2008. No obstante, las ciudades que sobresalieron en sus desempeños dinámicos fueron sin duda Lima y Bogotá, que mejoraron sus posiciones en catorce y cinco puestos respectivamente, entre 2001 y 2008, logrando ubicarse -este último periodo- entre las diez más competitivas de América Latina. Aparecen también con niveles relativamente altos de competitividad las ciudades de Río de Janeiro y Ciudad de México, que mejoraron dos posiciones durante el mismo periodo, además de las ciudades de Querétaro y Monterrey, que en 2007 se posicionaron como la tercera y sexta economías metropolitanas de mayor atracción de inversiones y negocios de América Latina; y aun cuando en 2008 bajaron sus posiciones al sexto y duodécimo lugar respectivamente, sus dinámicas recientes son sobresalientes, principalmente la referida a la ciudad mexicana de Querétaro, que entre 2002 y 2005 ni siquiera había sido considerada en la muestra objeto de estudio.

Las economías metropolitanas más rezagadas según el ranking fueron, por orden de importancia, las de las ciudades de Asunción, San José, Ciudad de Guatemala, Caracas, Guadalajara, Montevideo, Santo Domingo y Santa Cruz de la Sierra, que perdieron 12, 11, 11, 9, 9, 8,8 y 8 posiciones respectivamente, durante el periodo 2001-2008. En este contexto, es 
particularmente preocupante la situación de las ciudades de Asunción, Ciudad de Guatemala, Caracas y Santa Cruz de la Sierra, que tienen problemas de debilitamiento competitivo de carácter estructural asociados a restricciones políticas e institucionales -representadas en los altos márgenes de inseguridad jurídica, corrupción, inestabilidad política y delincuencia, sin considerar los temas ambientales- que incrementarían sustancialmente el riesgo de localización de inversiones y capitales extranjeros. No obstante, es interesante citar el caso de Sao Paulo, cuya extraordinaria dinámica económica de los últimos años y los beneficios de localización que conlleva, parecen haber compensado y sobrepasado a sus efectos adversos de carácter ambiental (América Economía, 2008). Las tendencias de mediano plazo (periodo 2005-2008) confirman algunos de estos procesos y muestran otros nuevos, donde, por ejemplo, se evidencia la vertiginosa ascendencia en niveles de posicionamiento competitivo de las ciudades de Bogotá y Lima, pero sobre todo de esta última, que en el periodo citado avanzó 18 posiciones (de la vigesimoséptima a la novena posición) convirtiéndose -con mucho- en la metrópoli latinoamericana de mejor desempeño relativo de la última década.

También aparecen como procesos novedosos de mediano plazo la recuperación económica de las ciudades de Buenos Aires, Río de Janeiro y Ciudad de México, que después de pasar por un periodo relativamente prolongado de pérdida de competitividad, mostraron visibles tendencias de mejoramiento: la primera durante los últimos cuatro años (del undécimo al quinto puesto) y las dos siguientes durante el último año (del decimoséptimo al séptimo puesto y del décimo al cuarto puesto, respectivamente). En el mediano plazo el grupo de ciudades perdedoras está conformado por Santo Domingo, Santa Cruz, Guadalajara, San José y Montevideo, pero especialmente las ciudades de Montevideo y Guadalajara, que durante el periodo 2005-2008 descendieron de los puestos decimosegundo y séptimo al vigésimo y decimoquinto lugar, respectivamente. También llama la atención los casos de las ciudades de Santa Cruz de la Sierra y Santo Domingo, pues durante los tres últimos ańos bajaron diez posiciones en el ranking de competitividad urbana latinoamericana (del puesto 25 al 35 y del puesto 31 al 41, respectivamente) que, en el caso de Santa Cruz de la Sierra, la convirtió en la penúltima ciudad del ranking.

\section{Externalidades urbanas y calidad de vida}

Como se sabe, la competitividad urbana está influenciada por la presencia de las denominadas economías externas que estimulan las aglomeraciones (fuerzas centrípetas) y por las denominadas deseconomías externas o externalidades negativas, interpretadas como las fuerzas centrífugas que frenan las aglomeraciones o concentraciones económico-poblacionales. Al igual que en el caso de las economías externas, las deseconomías externas adquieren este carácter al generarse fuera de las unidades productivas, firmas o empresas, por lo que pueden ser definidas como los procesos o dinámicas que se presentan en situaciones en las que existen beneficios decrecientes (costos crecientes) conforme aumenta la dimensión de la población (tamaño de la ciudad) o las actividades económicas. 


\section{CUADRO 4. POSICIONES EN EL RANKING DE COMPETITIVIDAD URBANA EN AMÉRI'̇A LATINA} (42 ciudades) $)^{+}(2001-2008)$

\begin{tabular}{|c|c|c|c|c|c|c|c|c|c|c|}
\hline \multirow{2}{*}{$\begin{array}{l}\text { Metrópolis principales de sud y } \\
\text { centroamérica ( } 42 \text { ciudades) }\end{array}$} & \multirow[b]{2}{*}{2001} & \multirow[b]{2}{*}{2002} & \multirow[b]{2}{*}{2003} & \multirow[b]{2}{*}{2004} & \multirow[b]{2}{*}{2005} & \multirow[b]{2}{*}{2006} & \multirow[b]{2}{*}{2007} & \multirow[b]{2}{*}{2008} & \multicolumn{2}{|c|}{ Cambio de posiciones } \\
\hline & & & & & & & & & (2001-2008) & (2005-2008) \\
\hline Sao Paulo & 2 & 1 & 2 & 3 & 3 & 1 & 4 & 1 & 1 & 2 \\
\hline Santiago & 3 & 3 & 2 & 1 & 1 & 2 & 1 & 3 & 0 & -2 \\
\hline Ciudad de México & 6 & 4 & 5 & 6 & 6 & 7 & 10 & 4 & 2 & 2 \\
\hline Buenos Aires & 3 & 6 & 9 & 11 & 10 & 9 & 5 & 5 & -2 & 5 \\
\hline Monterrey & 5 & 5 & 4 & 4 & 4 & 3 & 3 & 6 & -3 & -3 \\
\hline Rio de Janeiro & 9 & 10 & 12 & 13 & 14 & 16 & 17 & 7 & 2 & 7 \\
\hline Bogota & 13 & 16 & 16 & 14 & 13 & 12 & 11 & 8 & 5 & 5 \\
\hline Lima & 23 & 24 & 23 & 25 & 27 & 27 & 14 & 9 & 14 & 18 \\
\hline Curitiba & 7 & 7 & 6 & 5 & 5 & 5 & 7 & 10 & -3 & -5 \\
\hline Querétaro $^{2}$ & n.d. & n.d. & n.d. & n.d. & n.d. & 13 & 6 & 12 & 1 & 1 \\
\hline Guadalaraja & 7 & 8 & 7 & 7 & 7 & 6 & 8 & 15 & -9 & -9 \\
\hline Montevideo & 11 & 12 & 14 & 12 & 12 & 15 & 20 & 20 & -8 & -8 \\
\hline San Juan & n.d. & 15 & 15 & 15 & 17 & 24 & 24 & 21 & -6 & -4 \\
\hline San José & 15 & 14 & 13 & 17 & 16 & 17 & 22 & 25 & -11 & -9 \\
\hline Caracas & 24 & 25 & 28 & 35 & 36 & 39 & 42 & 34 & -9 & 2 \\
\hline Santo Domingo & n.d. & 27 & 21 & 26 & 25 & 28 & 18 & 35 & -8 & -10 \\
\hline Quito & n.d. & 35 & 36 & 31 & 32 & 33 & 39 & 37 & -2 & -5 \\
\hline Asunción & 25 & 26 & 27 & 38 & 38 & 40 & 40 & 38 & -12 & 0 \\
\hline Ciudad de Guatemala & n.d. & n.d. & 29 & 39 & 39 & 38 & 37 & 40 & -11 & -1 \\
\hline Santa Cruz de la Sierra & n.d. & 33 & 34 & 33 & 31 & 36 & 36 & 41 & -8 & -10 \\
\hline $\mathrm{La} \mathrm{Paz}$ & 34 & 37 & 35 & 40 & 42 & 41 & 41 & 42 & -5 & 0 \\
\hline
\end{tabular}

Las deseconomías externas son concebidas como los cambios desfavorables experimentados por ciertos agentes económicos (en este caso, una ciudad) a causa de las acciones unilaterales emprendidas por otro u otros agentes (población), cuyos dańos o costos no son procesados por el sistema de precios del mercado (Samuelson y Nordhuas, 1999; Martín Simón, 2003). En el ámbito urbano, las citadas deseconomías externas son de naturaleza múltiple y están referidas a problemas tales como: el incremento de la renta del suelo urbano, la contaminación del aire, el agua y el suelo, así como la excesiva congestión vehicular y la inseguridad ciudadana. Es importante mencionar, sin embargo, que aunque las deseconomías externas no tienen un precio de mercado, si tienen un valor (o más precisamente, un desvalor o perjuicio expresado en una pérdida de bienestar de la sociedad), razón por la cual se acude a un conjunto variado de métodos de estimación de sus impactos; aun cuando todas ellas son potencialmente medibles o estimables, en el presente estudio sólo haremos referencia a dos: la violencia o inseguridad ciudadana y el costo de vida o encarecimiento interno de precios (medido por las posibilidades de compra de un conjunto estándar de bienes y servicios), debido a que sus valores son incluidos en los informes anuales de la revista especializada de negocios América Economía y la consultora internacional Mercer Human Resources and Investment Consulting, para las principales ciudades de América Latina.

Las posiciones de cada ciudad latinoamericana según las ponderaciones cuantitativas y cualitativas de estas dos variables son presentadas en el Cuadro 5 para las 21 metrópolis latinoamericanas más atractivas para realizar negocios, donde se observa que los cinco mejores puestos en el caso de menor violencia lo tuvieron en 2006 y 2007, por orden de importancia, las ciudades 
de San Juan (puesto 72), Montevideo (puesto 76), Buenos Aires (puesto 78), Santiago (puesto 81 ) y Monterrey (puesto 94), de un conjunto de 215 ciudades de todo el mundo. Por su parte, las ciudades latinoamericanas que aparecen en 2006 con el más alto costo de vida a nivel mundial son: Sao Paulo (puesto 34), Río de Janeiro (puesto 40), San Juan (puesto 55), Santiago (puesto 91) y Monterrey (puesto 103); resalta el alto costo de vida de las ciudades brasileras, que se encuentran incluso encima de algunas ciudades del mundo desarrollado. Contrariamente, las ciudades más baratas fueron Asunción y Quito, aunque debe mencionarse que algunas otras como La Paz (Bolivia) no fueron consideradas en la muestra, e incorporaría niveles de costo de vida aún menores.

Por su parte, el nivel de la calidad de vida fue estimado a partir de los valores proporcionados por la consultora internacional Mercer Human Resources, que aun cuando resulta de la aplicación de una encuesta a ejecutivos que trabajan en multinacionales -lo que restringe ciertamente la objetividad de sus resultados- nos permite contar con una aproximación respecto de las "percepciones" sobre la calidad de vida y la influencia que tendría en la atracción y localización de inversiones extranjeras y/o recursos humanos calificados hacia determinadas economías metropolitanas. Estos resultados afortunadamente coinciden - en gran medida- con los obtenidos por otras metodologías de estimación de esta variable, como la utilizada por la revista The Economist (Economist Intelligent Unit) que mide la dificultad para vivir en las principales ciudades del mundo. Sin embargo, es menester aclarar que, dado que el concepto de calidad de vida es notoriamente amplio y sobre todo complejo (Leva, 2005; Gómez y Sabeh, 2001), los niveles o cuantificaciones utilizadas en este estudio no pasan de ser simples aproximaciones al fenómeno.

Tomando en cuenta la anterior restricción metodológica, pero siguiendo con el desarrollo del estudio, la medición de la relación ((costo de vida - calidad de vida) / calidad de vida), cuantificada en la última columna del Cuadro 5, verifica los resultados del ranking de competitividad obtenido, pues muestra que las ciudades de mayor avance relativo en términos de buena calidad de vida y/o bajo costo de vida fueron en 2006: Buenos Aires y Montevideo $(0,82)$, Asunción $(0,27)$, San José $(0,26)$, Quito $(0,19)$ y Santiago $(0,12)$. No obstante, si ordenamos los desempeños cualitativos de estas dos variables en una matriz de doble entrada a partir de datos presentados en la revista América Economía-tal cual se presenta en el Cuadro 6- podemos identificar aquellas que tienen altos niveles de vida y bajos costos de vida (como son los casos de Buenos Aires y Montevideo) y aquellas que tienen, contrariamente, una baja calidad de vida y un bajo costo de vida, como Caracas, Quito, Asunción y La Paz (principalmente influenciados por la existencia de altas tasas de inestabilidad política, inseguridad jurídica y corrupción). También podemos señalar estados combinados, como los registrados por Ciudad de México y Río de Janeiro, que muestran un alto costo de vida y una baja calidad de vida (influenciadas principalmente por las altas tasas de criminalidad y delincuencia), así como ciudades que presentan conjuntamente alta calidad y costo de vida, como es el caso de la ciudad de San Juan, cuya moneda oficial es el dólar estadounidense.

Como era de esperar, los casos intermedios constituyen la mayoría, donde, sin embargo, destacan aquellas ciudades que tienen una calidad de vida baja (o en ascenso) y un costo de vida medio, debido a las todavía prevalecientes altas tasas de pobreza y marginalidad, como son 
los casos de Bogotá, Lima, Caracas, Santo Domingo y Ciudad de Guatemala. Pero también aquellas ciudades con calidad de vida media (o en ascenso) y costo de vida alto, como Santiago y Monterrey, que por sus características tienen las mayores posibilidades de posicionarse en términos de competitividad en el mediano y largo plazo. Aun así, los casos de Lima y Bogotá son también promisorios, dado el sostenido crecimiento que mostraron en términos de productividad durante la última década. Debido a que la matriz del Cuadro 6 es de carácter estático, se incorpora en el Cuadro 7 su complemento en términos dinámicos, a través de una comparación de los desempeños de las citadas dos variables (costo y calidad de vida) durante el periodo 2004-2007, donde se observa que sólo Buenos Aires y Montevideo mejoraron sus estándares de vida con un sistema de precios bajos (situación óptima). Contrariamente, en la vereda del frente se encuentran ciudades como Lima, Quito y Asunción, donde se evidencian altos, pero sobre todo crecientes precios internos acompañados de situaciones de empeoramiento de la calidad de vida, ya sea por la escalada de la delincuencia y la inseguridad ciudadana, por la presencia cada vez más marcada de problemas ambientales, conflictos sociales, pobreza, marginalidad, corrupción o por una combinación de ellos.

\section{CUADRO 5. APROXIMACIONES DE NIVELES DE CALIDAD DE VIDA, DIFICULTAD PARA VIVIR Y COSTO DE VIDA EN CIUDADES DE AMÉRICA LATINA (2006)}

\begin{tabular}{|c|c|c|c|c|c|c|}
\hline $\begin{array}{c}\text { Ciudades de } \\
\text { América Latina }\end{array}$ & $\begin{array}{c}\text { Calidad de } \\
\text { vida }^{1}(\mathrm{~A})\end{array}$ & $\begin{array}{c}\text { Dificultad } \\
\text { para vivir }{ }^{2}(B)\end{array}$ & $\begin{array}{c}\text { Costo de vida }{ }^{3} \\
\text { (C) }\end{array}$ & $\begin{array}{l}\text { Calidad } \\
\text { de vida }\end{array}$ & $\begin{array}{c}\text { Costo de } \\
\text { vida }\end{array}$ & $\begin{array}{c}\text { Relación } \\
(\mathrm{C}-\mathrm{A}) / \mathrm{A}\end{array}$ \\
\hline Sao Paulo & 108 & 85 & 34 & Media & Alto & $(0,69)$ \\
\hline Santiago & 81 & 66 & 91 & Alta & Medio & 0,12 \\
\hline Ciudad de México & 128 & 106 & 81 & Baja & Alto & $(0,37)$ \\
\hline Buenos Aires & 78 & 67 & 142 & Alta & Bajo & 0,82 \\
\hline Monterrey & 94 & n.d. & 103 & Alta & Medio & 0,10 \\
\hline Rio de Janeiro & 117 & 82 & 40 & Baja & Alto & $(0,66)$ \\
\hline Bogota & 143 & 116 & 130 & Baja & Medio & $(0,09)$ \\
\hline Lima & 132 & 88 & 117 & Baja & Medio & $(0,11)$ \\
\hline Montevideo & 76 & 65 & 138 & Alta & Bajo & 0,82 \\
\hline San Juan & 72 & 62 & 55 & Alta & Alto & $(0,24)$ \\
\hline San José & 106 & 63 & 134 & Media & Medio & 0,26 \\
\hline Caracas & 140 & 103 & 136 & Baja & Medio & $(0,03)$ \\
\hline Santo Domingo & 130 & n.d. & 126 & Baja & Medio & $(0,03)$ \\
\hline Quito & 118 & 93 & 141 & Baja & Bajo & 0,19 \\
\hline Asunción & 113 & 96 & 144 & Baja & Bajo & 0,27 \\
\hline Ciudad de Guatemala & 140 & 105 & 107 & Baja & Medio & $(0,24)$ \\
\hline $\mathrm{La} \mathrm{Paz}$ & 140 & n.d. & n.d. & Baja & $\mathrm{Bajo}^{3}$ & n.d. \\
\hline
\end{tabular}

Fuente: Elaboración propia con base en datos de Mercer Human Resource Consulting y The Economist

' Mercer Human Resource Consulting . Ranking de 215 ciudades de todo el mundo, donde la de mayor calidad de vida ocupa el puesto 1 y la de menor, el 215.

2 The Economist. Ranking de 130 ciudades de todo el mundo, donde la de menor dificultad para vivir ocupa el puesto 1 y la de mayor, el 130 . Datos para el 2005.

${ }^{3}$ Mercer Human Resource Consulting. Ranking de 144 ciudades de todo el mundo, donde la de mayor costo de vida ocupa el puesto 1 y la de menor, el 144.

${ }^{4}$ Dato estimado en función al costo de la canasta básica de alimentos y servicios (2007) 
CUADRO 6, RELACIÓN ENTRE CALIDAD Y COSTO DE VIDA EN CIUDADES DE AMÉRICA LATINA (2006)

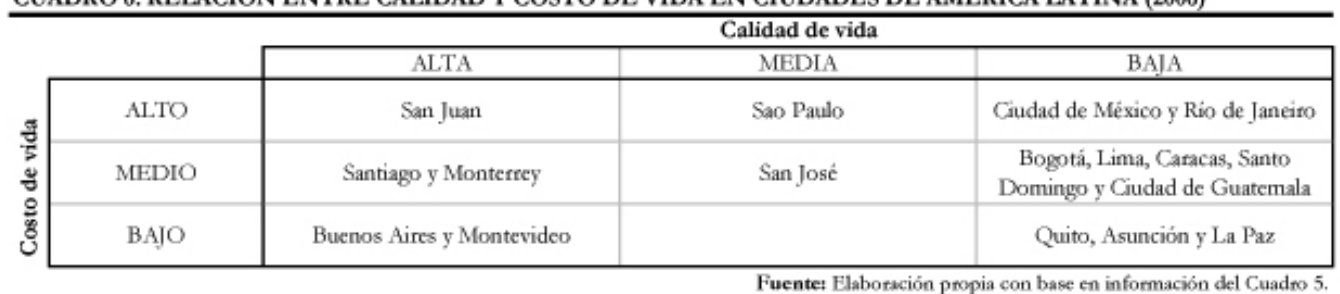

CUADRO 7. CAMBIO EN LOS VALORES DE LA CALIDAD Y COSTO DE VIDA DE LAS CIUDADES DE AMÉRICA LATINA (2004-2007)

\begin{tabular}{|c|c|c|c|}
\hline \multicolumn{1}{c|}{} & MEJOR & Calidad de vida \\
\cline { 2 - 5 } \multicolumn{1}{c|}{} & IGUAL & PEOR \\
\hline & MAS BARATO & Saenos Aires y Montevideo & Có y La Paz \\
\hline
\end{tabular}

Los casos de ciudades que durante el periodo 2004-2007 mantuvieron la calidad de vida pero con crecientes costos de vida, es decir, con precios internos altos, constituyen la mayoría (Sao Paulo, Bogotá, Río de Janeiro, Santo Domingo, San Juan, Santa Cruz y Ciudad de Guatemala). Finalmente, tenemos ciudades que aun cuando incorporan indicadores de mejora sustancial en la calidad de vida, lo hacen manteniendo niveles constantes de precios internos (Monterrey) o incluso aumentando sus costos de vida, como es el caso de Santiago de Chile; y ciudades que manteniendo sus estándares de vida muestran tendencias coyunturales de disminución de los precios internos de acceso a la canasta básica, como son los casos de San José y La Paz; o ciudades que manteniendo sus costos de vida muestran tendencias de empeoramiento de su calidad de vida, como es el caso de Ciudad de México. Es importante, sin embargo, no perder de vista que todos los indicadores citados son de carácter relativo, es decir, que están referidos a niveles en la calidad y costo de vida que tienen como referencia a una ciudad en particular, que en el caso del estudio presentado por la revista América Economía, fue la ciudad de Miami, que actuó como referente regional.

No obstante, si con base en los valores de los niveles de violencia y costo de vida se ajustan los PIB pc de las 21 ciudades latinoamericanas analizadas, y posteriormente se las relaciona con sus respectivos PIB pc corrientes para el 2006, se observa que ciertas economías urbanas muestran avances sobresalientes (identificados por un valor mayor a 1 en la segunda columna del Cuadro 8). Destacan las ciudades de La Paz $(1,80)$, Asunción $(1,65)$, Montevideo $(1,56)$ y Buenos Aires $(1,41)$; sin embargo, en la información del Cuadro 7 se aprecia que las economías urbanas de las ciudades de La Paz, Quito y Asunción están visiblemente influenciadas por la disminución del costo de vida, en tanto que las demás, por la mejora de la calidad de vida. Contrariamente, existen casos como los de Río de Janeiro y Ciudad de Guatemala $(0,83)$, Santo Domingo $(0,92)$ y Ciudad de México $(0,91)$, que verifican la visible presencia de problemas asociados a la delincuencia y la violencia que disminuyen sus PIB pc ajustado. 
También para el análisis en términos dinámicos, en la tercera columna del Cuadro 8 se presenta información sobre el crecimiento promedio anual del PIB pc ajustado del periodo 2003-2006, que en algunos casos confirma el escenario anteriormente descrito, con altas tasas promedio de crecimiento (como son los casos de Monterrey, Buenos Aires, Montevideo, Santiago y Curitiba) o con tasas negativas (como son los casos de Santo Domingo, Ciudad de Guatemala, Sao Paulo y Lima). Pero que también muestran situaciones de ciudades donde aun cuando sus PIB pc ajustados fueron menores a sus PIB pc corrientes en 2006, despliegan tasas positivas de crecimiento promedio entre 2003-2007 (por ejemplo, Ciudad de México y Río de Janeiro). Este fenómeno muestra que aun cuando es todavía preocupante la presencia de niveles altos de delincuencia e inseguridad ciudadana, de todos modos existirían avances sustanciales en los últimos años en términos de PIB pc. Contrariamente, existen casos en los que, si bien en 2006 la relación PIB pc ajustado vs PIB pc corriente fue positiva, las tasas de crecimiento del PIB pc ajustado 2003-2007 son negativas. Esto muestra que aun cuando algunas economías mejoraron en el corto plazo, su situación a largo plazo es negativa, este es el caso, por ejemplo, de las ciudades de La Paz y Asunción.

El panorama anterior puede ser analizado a partir de la información incorporada en la Figura 3, donde se relacionan el PIB pc y algunas externalidades urbanas negativas, como el incremento en la violencia, la contaminación, los conflictos sociales, la congestión y el costo de vida, entre otras, las cuales pueden ser eventualmente internalizadas en la medición de los PIB pc corrientes para obtener PIB pc ajustados. No obstante, si se ajusta los PIB pc corrientes de las principales metrópolis de América Latina según violencia y costo de vida y se los relaciona con sus PIB pc corrientes, se rechaza de inicio la hipótesis de que las citadas externalidades negativas estén actuando como factores restrictivos de la eficiencia de los sistemas económicos metropolitanos. Se observa que en general las ciudades con los mayores PIB pc corrientes incorporan paralelamente los menores valores de la relación PIB pc ajustado / PIB pc corriente, debido a sus presumibles altos niveles de violencia y/o costo de vida, fenómeno que respalda la hipótesis de que aun cuando se evidencia la presencia de ciertas altas externalidades negativas en algunas grandes urbes latinoamericanas, estas no habrían frenado sus desempeños económicos expresados en sus niveles de productividad. Para un análisis que respalda el anterior resultado, se puede consultar Galindo et al. (2004, p. 296), donde a partir de un estudio del estado del arte sobre crecimiento y urbanización -con énfasis en el caso de la Ciudad de México- establecen que "la evidencia empírica sugiere que en la suma neta de las externalidades (urbanas) positivas y negativas, dominan las primeras”. De manera similar en Galetovic (2006) se confirman algunas de las relaciones descritas, a partir de un análisis sobre las interconexiones teóricas y empíricas entre crecimiento económico, urbanización y externalidades, para el caso de la ciudad de Santiago de Chile.

El análisis desagregado de los efectos de la violencia y el costo de vida muestra que sólo la baja violencia estaría actuando como factor real de incentivo para el incremento de la productividad urbana en América Latina, cuyos ejemplos más ilustrativos son las ciudades de Santiago, Monterrey, Querétaro y, en menor medida, Montevideo, San Juan y San José. Ciudades baratas como La Paz, Asunción, Ciudad de Guatemala o Quito no logran utilizar este factor como eventual incentivo para atraer nuevas inversiones, en tanto que ciudades violentas y caras como Sao Paulo, Ciudad de México, Río de Janeiro y Bogotá sí lo estarían logrando. No obstante, 
es importante mencionar que la referencia sobre externalidades negativas no consideró otras variables, como las de la dimensión ambiental, cuya adecuada gestión podría muy bien estar actuando como mecanismo paralelo de atracción de recursos financieros y humanos externos que paulatinamente mejoren sus niveles de productividad.

\section{CUADRO 8. PIB AJUSTADO EN PRINCIPALES METRÓPOLIS DE AMÉRICA LATINA}

\begin{tabular}{|c|c|c|c|}
\hline $\begin{array}{l}\text { Metrópolis principales } \\
\text { de sud y centroamérica }\end{array}$ & $\begin{array}{c}\text { PIB per cápita } \\
\text { con ajuste al costo de } \\
\text { vida y violencia }(2006) *\end{array}$ & $\begin{array}{l}\text { Relación entre el PIB } \\
\text { per cápita ajustado y el } \\
\text { PIB corriente }(2006) * *\end{array}$ & $\begin{array}{l}\text { Crecimiento promedio } \\
\text { anual del PIB per cápita } \\
\text { ajustado (2003-2006) }\end{array}$ \\
\hline Sao Paulo & 6.340 & 1,00 & $(5,8)$ \\
\hline Santiago & 10.984 & 1,30 & 9,1 \\
\hline Ciudad de México & 11.524 & 0,91 & 19,8 \\
\hline Buenos Aires & 11.118 & 1,41 & 17,7 \\
\hline Monterrey & 15.916 & 1,17 & 33,4 \\
\hline Rio de Janeiro & 5.180 & 0,83 & 8,7 \\
\hline Bogota & 5.259 & 1,27 & 4,8 \\
\hline Lima & 3.340 & 1,00 & $(10,5)$ \\
\hline Curitiba & 7.980 & 1,21 & 20,2 \\
\hline Querétaro $^{1}$ & 9.213 & 1,08 & n.d. \\
\hline Guadalajara & 10.504 & 1,13 & 16,7 \\
\hline Montevideo & 6.620 & 1,56 & 11,1 \\
\hline San Juan & 15.627 & 1,07 & 31,3 \\
\hline San José & 6.484 & 1,36 & 17,7 \\
\hline Caracas & 6.773 & 1,07 & 26,9 \\
\hline Santo Domingo ${ }^{1}$ & 2.472 & 0,92 & $(12,0)$ \\
\hline Quito & 3.120 & 1,37 & 19,1 \\
\hline Asunción & 2.376 & 1,65 & $(11,4)$ \\
\hline Ciudad de Guatemala & 2.261 & 0,83 & $(15,1)$ \\
\hline Santa Cruz de la Sierra & 1.491 & 1,30 & 4,2 \\
\hline $\mathrm{La} \mathrm{Paz}^{2}$ & 1.731 & 1,80 & $(7,5)$ \\
\hline & Fuente: Elaboración propia & $\begin{array}{r}\text { con base en datos de la CEPAI } \\
* \text { En mill } \\
{ }^{1} \text { Considera el crecimiento del }\end{array}$ & $\begin{array}{l}\text { y la revista América Economía. } \\
\text { nes de dólares americanos corrientes } \\
* * \text { En dólares americanos corrientes } \\
\text { IB per cápita del periodo 2006-2007 }\end{array}$ \\
\hline
\end{tabular}




\section{FIGURA 3. AMÉRICA LATINA: PIB PER CÁPITA Y EXTERNALIDADES URBANAS NEGATIVAS (2007)}

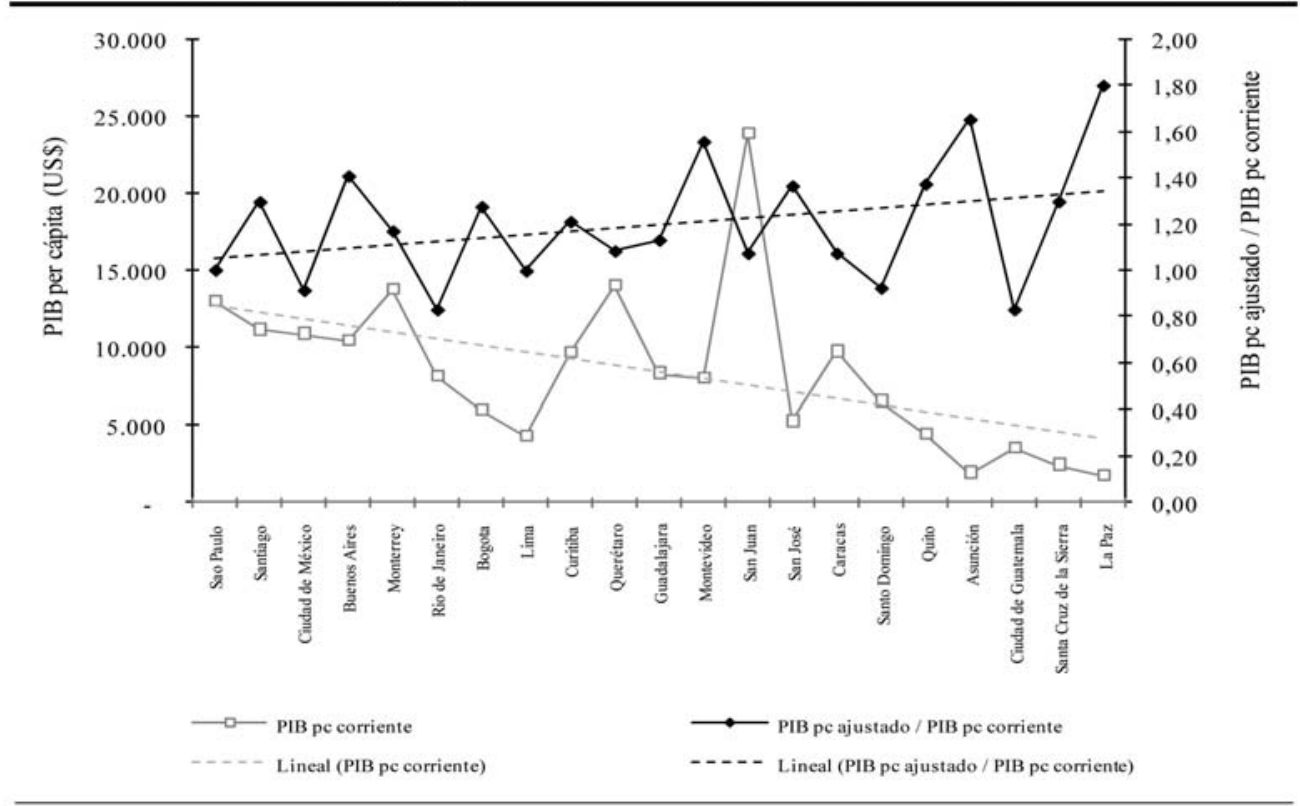

Fuente: Elaboración propia con base en información de la revista América Economia

\section{Descripción de algunos de los factores determinantes de la competitividad urbana}

\section{El factor geográfico-locacional}

La bibliografía especializada muestra que las condiciones geográficas de un país, la dotación de recursos naturales y la locación, son factores que influencian decididamente en los niveles de competitividad territorial (Hausmann, 2001; Gallup, et al., 1998; Sachs y Wagner, 1997). De un modo similar, ciertos estudios de geografía económica, sostienen que los sistemas montañosos y/o zonas tropicales presentes en gran parte de un territorio representarían una seria desventaja comparativa en términos de competitividad, dados los altos costos del transporte (CEPAL, 2003a y Gallup, 2000). También en este sentido, un estudio elaborado por la CEPAL (2003b) demuestra que en Sudamérica los países que tienen los mayores costos de transporte de internación de productos del exterior son Paraguay, Bolivia, Perú, Ecuador y Colombia, y que -con excepción del primero- son precisamente territorios por los que atraviesa la cordillera de los Andes. Si a la situación anteriormente descrita añadimos la condición de mediterraneidad (Bolivia y Paraguay), se vuelve a verificar la notable influencia que tendría el componente geográfico-locacional en los niveles de competitividad de los países y de sus economías internas. Por su parte, Cárcamo-Díaz (2004) muestra cómo el costo de transporte de productos de comercio exterior en países sudamericanos sin litoral marítimo aumenta considerablemente debido a la geografía; pero también lo hace el costo administrativo de internación de mercancías por las prolongadas distancias, situación que, no obstante, debe relativizarse en función de la calidad de la infraestructura vial, dados los casos de Santiago de Chile, Ciudad de México y Bogotá, que sin ser ciudades-puerto muestran niveles relativamente altos de competitividad urbana. 
La dotación relativa de recursos naturales también influye en los niveles de competitividad de las naciones y sus economías urbano-regionales. La etapa inicial de creación de competitividad por la que pasan gran parte de las economías latinoamericanas tiene como característica principal su perfil productor primario, como son los casos de Venezuela, Ecuador y Bolivia (cuyas matrices productivas son altamente dependientes de la explotación de hidrocarburos) y en menor medida Perú, Chile y Argentina (asociados a la producción minera y agropecuaria). Por ello, aunque la relación entre la dotación de recursos naturales y los niveles de competitividad no es de ninguna manera directa, mucho menos si se la asocia con las economías urbanas, llama la atención que las ciudades capitales de Venezuela, Ecuador y Bolivia estén posicionadas entre las de menor competitividad en el contexto latinoamericano. El condicionamiento respecto a la dotación de recursos naturales se verifica a partir de la información del Cuadro 9, donde se observa que las primeras cinco de las 25 mayores empresas de América Latina -ordenadas según valor de ventas, número de empleados y valor de exportaciones- operan en el sector hidrocarburos (dos en México, dos en Brasil y una en Venezuela), además de que algo más de la mitad de todas ellas - 13 en total- pertenecen a los sectores de petróleo/gas (7), petroquímica (1), minería (2), siderurgia/metalurgia (2) y cemento (1). Este panorama respalda la estratégica importancia de la producción de materias primas y sus principales derivados manufacturados en las economías de los países de la región, que aun cuando se producen normalmente fuera de los límites administrativos de las ciudades, tienen un visible impacto en ellas, principalmente en forma de consumo, pero también en forma de abaratamiento de los precios de ciertos insumos productivos provenientes de la industrialización de materias primas.

\section{El factor tecnológico y la revolución terciaria}

No es desconocida la importancia que tiene el factor tecnológico en los procesos productivos. Por ello, el uso de las denominadas nuevas tecnologías de la información y la comunicación (TIC) y el desarrollo de la base infraestructural de las telecomunicaciones son indicadores cada vez más confiables y más utilizados para efectos de determinar el grado de avance que tiene una economía -en este caso, una economía urbana- en términos de posicionamiento competitivo. Esto es así debido a que la tecnología actúa como uno de los principales factores de expansión de la producción mediante el incremento de la productividad, la disminución de tiempos de trabajo y/o simplificación de procesos. Al respecto, la revista América Economía, que cuantifica e incorpora anualmente -entre sus indicadores de medición de ranking de competitividad urbana- a las variables conectividad digital y penetración de telefonía móvil y de líneas de banda ancha (Cuadro 10), muestra que en 2008 las mayores conectividades digitales urbanas en América Latina las tuvieron las ciudades de Sao Paulo, Santiago, Río de Janeiro, Curitiba y Montevideo (con niveles buenos de conectividad digital), en tanto que las más rezagadas fueron las ciudades de Lima, San Juan, San José, Quito, Ciudad de Guatemala, Santa Cruz de la Sierra y La Paz (con niveles deficientes de conectividad digital). Estas tendencias -en ambos casos- parecen mantenerse relativamente constantes durante los últimos años.

Un panorama similar se presenta en el caso de los niveles de penetración (conexiones por cada 100 habitantes) en telefonía móvil y en líneas de banda ancha, cuyos mejores desempeños en 2007 y 2008 según América Economía estuvieron localizados en las ciudades de Buenos Aires (115), Ciudad de México (93), San Juan (90), Lima (81) y Santiago (80) en el caso de 
líneas telefónicas móviles; y en las ciudades de Santiago (11,9), Caracas (7,9), Sao Paulo $(6,2)$, Buenos Aires $(5,2)$ y Bogotá $(4,7)$ en el caso de líneas de banda ancha. Al respecto, la Unión Internacional de Telecomunicaciones (UIT) confirma que entre 1990 y 2005 la evolución de las telecomunicaciones en América Latina ha sido espectacular, pues se ha multiplicado por tres la penetración de telefonía fija, en tanto que las líneas móviles se han incrementado de 100.000 a 233.000 millones. El mercado de banda ancha, por su parte, habría crecido en el mismo periodo a un promedio anual de $85 \%$, pues los datos muestran que hasta finales de 2005 América Latina habría multiplicado por 6,7 el número de abonados a Internet de Banda Ancha respecto de 2001. Se aprecia también que la venta de computadoras en América Latina en 2005 tuvo un crecimiento promedio del 26\% respeto al 15\% registrado a nivel mundial. Finalmente, respecto a las conexiones de líneas de Internet inalámbricas (internet in the air) se observa que hasta el 2006 lideraba ampliamente la ciudad de Sao Paulo, pues según datos de la revista América Economía (2007), este año había registrado 640 puntos de conexión, cantidad mucho mayor a la registrada en ciudades como Santiago de Chile (204) y Ciudad de México (174), entre otras, mostrando la verdadera "revolución digital” que se estaría generando en esta ciudad.

\begin{tabular}{|c|c|c|c|c|c|c|}
\hline Paises y mayores empresas & $\begin{array}{c}\text { Posición en } \\
\text { ranking }\end{array}$ & $\begin{array}{c}\text { Sector de } \\
\text { actividad principal }\end{array}$ & $\begin{array}{l}\text { Valor de } \\
\text { ventas* }\end{array}$ & $\begin{array}{c}\text { Utilidad } \\
\text { neta* }\end{array}$ & Empleados & Exportaciones* \\
\hline \multicolumn{7}{|l|}{ México } \\
\hline PEMEX REFINACION & 4 & Petróleo / Gas & 43.494 & -4.218 & 48.000 & n.d. \\
\hline AMERICA MOVIL & 6 & Telecomunicaciones & 28.544 & 5.367 & 45.646 & 0 \\
\hline WAL-MART DE MEXICO & 10 & Comercio & 20.610 & 1.303 & 157.432 & 0 \\
\hline PEMEX GAS Y PETROQUIMICA BASICA & 11 & Petroquímica & 20.514 & 455 & 12.500 & 2.301 \\
\hline FEMSA & 18 & Bebidas / Licores & 13.517 & 779 & 105.020 & 4.345 \\
\hline TELEFONOS DE MEXICO & 21 & Telecomunicaciones & 11.979 & 3.250 & 79.000 & 0 \\
\hline TELCEL & 24 & Telecomunicaciones & 11.628 & n.d. & 14.360 & 0 \\
\hline PETROBRAS DISTRIBUIDORA & 8 & Petróleo / Gas & 20.721 & 474 & n.d. & 656 \\
\hline GRUPO VOTORANTIM & 13 & Multisector & 17.144 & 2.708 & 50.000 & n.d. \\
\hline GERDAU & 15 & Siderurgia / Metalurgia & 15.814 & 1.616 & 36.925 & n.d. \\
\hline ODEBRECHT & 16 & Multisector & 14.885 & 254 & 58.996 & 6.005 \\
\hline DIST. DE PROD. DE PETROLEO IPIRANGA & 17 & Petróleo / Gas & 13.846 & 91 & 2.430 & n.d. \\
\hline ELETROBRAS & 19 & Electricidad & 12.676 & 874 & 26.177 & 0 \\
\hline VOLKSWAGEN DE BRASIL & 22 & Automotriz / Autopartes & 11.950 & n.d. & 17.500 & 2.126 \\
\hline CIA. BRASILERA DE PETROLEO IPIRANGA & 23 & Petróleo / Gas & 11.753 & 215 & n.d. & n.d. \\
\hline \multicolumn{7}{|l|}{ Chile } \\
\hline CODELCO & 14 & Minería & 16.988 & 2.982 & 18.211 & 14.742 \\
\hline EMPRESAS COPEC & 20 & Multisector & 12.275 & 1.010 & 12.300 & n.d. \\
\hline
\end{tabular}


CUADRO 10. CONECTIVIDAD DIGITAL Y POTENCIAL INNOVADOR EN CIUDADES DE AMÉRICA LATINA (2007 Y 2008)

\begin{tabular}{|c|c|c|c|c|}
\hline $\begin{array}{l}\text { Principales ciudades } \\
\text { de América Latina }\end{array}$ & $\begin{array}{c}\text { Conectividad } \\
\text { digital }^{1}\end{array}$ & $\begin{array}{l}\text { Penetración } \\
\text { telefónica }^{\text {movil }}{ }^{2}\end{array}$ & $\begin{array}{c}\text { Penetración de } \\
\text { internet } \mathbf{B A}^{3}\end{array}$ & $\begin{array}{l}\text { Potencial } \\
\text { innovador }\end{array}$ \\
\hline Sao Paulo & Buena & 74,1 & 6,2 & Aceptable \\
\hline Santiago & Buena & 80,4 & 11,9 & Aceptable \\
\hline Ciudad de México & Regular & 93,0 & 4,6 & Aceptable \\
\hline Buenos Aires & Buena & 115,0 & 5,2 & Aceptable \\
\hline Monterrey & Regular & 73,5 & 3,1 & Aceptable \\
\hline Rio de Janeiro & Buena & 79,4 & 4,2 & Aceptable \\
\hline Bogota & Regular & 70,0 & 4,7 & Bajo \\
\hline Lima & Deficiente & 81,1 & 3,8 & Bajo \\
\hline Curitiba & Buena & 77,0 & 4,5 & Bueno \\
\hline Querétaro & Regular & 62,4 & 2,0 & Aceptable \\
\hline Guadalajara & Regular & 63,4 & 2,5 & Aceptable \\
\hline Montevideo & Buena & 80,0 & 0,6 & Bueno \\
\hline San Juan & Deficiente & 90,5 & 3,9 & Bajo \\
\hline San José & Deficiente & 32,3 & 2,7 & Bajo \\
\hline Caracas & Regular & 80,3 & 7,9 & Aceptable \\
\hline Santo Domingo & Regular & 55,7 & 0,1 & Bajo \\
\hline Quito & Deficiente & 73,1 & 0,1 & Bajo \\
\hline Asunción & Regular & 53,8 & 0,3 & Bajo \\
\hline Ciudad de Guatemala & Deficiente & 75,0 & 0,3 & Bajo \\
\hline Santa Cruz de la Sierra & Deficiente & 35,7 & 0,6 & Bajo \\
\hline $\mathrm{La} \mathrm{Paz}$ & Deficiente & 30,3 & 0,5 & Bajo \\
\hline \multicolumn{5}{|c|}{ Fuente: Revista América Economía } \\
\hline \multicolumn{5}{|c|}{${ }^{1}$ Datos para el periodo 2007} \\
\hline \multicolumn{5}{|c|}{${ }^{2}$ Líneas móviles por cada 100 habitantes. Datos para el periodo 2008} \\
\hline \multicolumn{5}{|c|}{${ }^{3}$ Líneas con banda ancha por cada 100 habitantes. Datos para el periodo 2008} \\
\hline & & & & ${ }^{4}$ Periodo 2007 \\
\hline
\end{tabular}

La información especializada también verifica la tendencia generalizada de ascenso de la participación del sector servicios en las estructuras económicas de las ciudades, donde resalta el dinamismo pero sobre todo la concentración del sector financiero, más precisamente del sector bancario. Al respecto, la información del Cuadro 11 evidencia que en 2008, 18 de los 25 mayores bancos de América Latina estuvieron localizados en Brasil, México y Chile (8, 5 y 5 bancos, respectivamente), cuyos activos conjuntos sumaron US $\$ 881.500$ millones (95\% del total de activos bancarios de los 25 mayores bancos de América Latina). Los restantes siete mayores estuvieron localizados en Colombia (4), Perú (2) y Paraguay (1). Esta situación muestra, por lo tanto, la creciente participación de los mercados financieros en las economías urbanas de América Latina, particularmente en los centros urbanos más competitivos, entre los que destacan Sao Paulo, Ciudad de México y Santiago de Chile, donde la revolución digital estaría acompañada de una revolución terciaria (Garza, 2006).

\section{El factor humano y la innovación}

La fuente originaria del avance tecnológico y de la mejora en los niveles de productividad, así como de la generación de ingreso y, por lo tanto, del incremento de la calidad de vida de una sociedad es, sin duda, el propio ser humano y su infinita capacidad para resolver problemas 
a través de la creación y la innovación. Es por ello que el factor humano, en forma de capacitación e innovación canalizada mediante recursos públicos o privados hacia labores de investigación y desarrollo (I \& D), es el que permite -en última instancia- la incorporación y búsqueda permanente, por parte de las unidades productivas, de nuevos productos, servicios y compradores, así como de nuevos procesos, sistemas y modelos de gestión.

CUADRO 11. LOS 25 MAYORES BANCOS DE AMÉRICA LATINA (2007)

\begin{tabular}{|c|c|c|c|c|c|c|}
\hline Paises y mejores bancos & $\begin{array}{l}\text { Posición en } \\
\text { ranking }\end{array}$ & $\begin{array}{l}\text { Activos totales } \\
\text { (mill.de US\$) }\end{array}$ & $\begin{array}{l}\text { Colocaciones / } \\
\text { Patrimonio (\%) }\end{array}$ & $\begin{array}{c}\text { Eficiencia }^{1} \\
(\%)\end{array}$ & $\begin{array}{c}\text { Rendimiento } \\
(\%)\end{array}$ & $\begin{array}{c}\text { Liquidez }^{3} \\
(\%)\end{array}$ \\
\hline \multicolumn{7}{|l|}{ Brasil } \\
\hline CITYBANK & 7 & 21.095 & 6,0 & 63,9 & 31,2 & 4,6 \\
\hline SAFRA & 11 & 37.113 & 5,9 & 67,5 & 22,8 & 1,7 \\
\hline $\mathrm{ABN}$ & 12 & 81.549 & 9,2 & 56,1 & 20,4 & 2,4 \\
\hline BRADESCO & 13 & 134.252 & 3,3 & 61,1 & 29,1 & 4,0 \\
\hline UNIBANCO & 15 & 62.252 & 4,2 & 61,1 & 26,3 & 3,1 \\
\hline HSBC & 16 & 35.214 & 7,4 & 75,9 & 24,3 & 2,9 \\
\hline SANTANDER BRASIL & 20 & 58.714 & 5,3 & 59,6 & 19,2 & 2,5 \\
\hline ITAU & 25 & 126.235 & 4,6 & 84,0 & 23,3 & 2,5 \\
\hline \multicolumn{7}{|l|}{ México } \\
\hline BBVA BANCOMER & 2 & 61.939 & 5,9 & 50,8 & 26,7 & 25,8 \\
\hline BANORTE & 6 & 23.261 & 5,8 & 51,7 & 21,2 & 26,8 \\
\hline SANTANDER MEXICO & 8 & 35.145 & 3,9 & 61,0 & 14,9 & 32,7 \\
\hline BANAMEX & 10 & 48.340 & 2,1 & 56,1 & 15,3 & 22,3 \\
\hline HSBC & 21 & 28.726 & 5,0 & 86,4 & 14,1 & 21,8 \\
\hline \multicolumn{7}{|l|}{\begin{tabular}{|l} 
Chile \\
\end{tabular}} \\
\hline SANTANDER SANTIAGO & 1 & 30.781 & 9,9 & 32,2 & 24,9 & 13,9 \\
\hline DE CHILE & 4 & 25.990 & 13,4 & 48,1 & 25,3 & 17,1 \\
\hline SECURITY & 9 & 4.567 & 11,4 & 30,5 & 18,0 & 4,0 \\
\hline $\mathrm{BCI}$ & 14 & 18.533 & 12,7 & 42,6 & 17,5 & 14,0 \\
\hline $\mathrm{BICE}$ & 22 & 4.067 & 9,8 & 62,4 & 17,9 & 7,9 \\
\hline \multicolumn{7}{|l|}{ Colombia } \\
\hline BBVA COLOMBIA & 17 & 7.893 & 8,0 & 56,9 & 24,9 & 6,9 \\
\hline POPULAR & 18 & 3.964 & 6,0 & 54,6 & 24,7 & 8,9 \\
\hline DE OCCIDENTE & 19 & 4.938 & 5,3 & 56,9 & 18,1 & 11,6 \\
\hline DE BOGOTA & 23 & 10.205 & 5,0 & 55,4 & 18,5 & 9,2 \\
\hline \multicolumn{7}{|l|}{ Perú } \\
\hline CREDITO & 3 & 10.181 & 5,6 & 49,5 & 35,0 & 28,2 \\
\hline CONTINENTAL BBVA & 5 & 6.425 & 8,8 & 43,9 & 33,5 & 21,0 \\
\hline \multicolumn{7}{|l|}{\begin{tabular}{|l|} 
Paraguay \\
\end{tabular}} \\
\hline GENERAL & 24 & 3.736 & 6,5 & 52,4 & 19,8 & 10,8 \\
\hline \multicolumn{7}{|c|}{ Fuente: Elaboración propia con base en datos de la revista América Economía } \\
\hline & & & ${ }^{1}$ Gastos of & peracionales y & de personal sobre & margen bruto \\
\hline & & & & & ${ }^{2}$ Utilidades sob & re patrimonio \\
\hline
\end{tabular}

Los citados procesos de innovación en América Latina están lamentablemente muy rezagados, pues en 2006 esta región en su conjunto invirtió menos del 0,5\% de su PIB en I \& D, muy por debajo de los promedios de otras regiones del mundo subdesarrollado, sin citar al mundo desarrollado. Se observa al respecto que el país de mejor desempeño en Latinoamérica en 2006 fue Chile, que en una escala (1, peor desempeño y 7, mejor desempeño) obtuvo a nivel internacional un 4,09 (puesto 32 de 117 países), seguido por Brasil (4,03), Costa Rica $(4,01)$, Colombia $(3,74)$ y Argentina $(3,72)$; como era previsible, los de peor desempeño en innovación fueron Bolivia (2,57) y Paraguay (2,58 / puesto 115). 
En el ámbito urbano, según la revista América Economía (2006), se destacaron por sus procesos de creación e innovación las ciudades de Sao Paulo (con una ponderación de 4,6; considerando un valor de 7,0 a la mejor evaluación), Bogotá $(4,5)$, Santiago y Buenos Aires $(4,4)$ y Ciudad de México $(3,9)$. De forma similar, destacan como los centros de mayor creación de nuevas tecnologías las ciudades de Sao Paulo (con 23\% aceptación del total de encuestados) y Santiago (17\%). La producción académica de estas ciudades verifica estos desempeños, pues según la revista América Economía (2008a) la producción de papers ISI (2005-2007) está liderada por Sao Paulo (21.531 investigaciones científicas publicadas), seguido por Ciudad de México (13.652) y Buenos Aires (9.622). El descrito liderazgo de Sao Paulo, Santiago, Ciudad de México, Buenos Aires y Bogotá se confirma a partir de la información sobre los programas académicos de MBA de América Latina (América Economía, 2008c), donde se observa que 19 de los 25 mejores están localizados en cuatro países: México (6), Chile (6), Argentina (4) y Brasil (3), incluyendo 7 de los 10 mejores. Estos centros académicos tienen también los mayores volúmenes de plantillas docentes (profesores a dedicación exclusiva con grados de doctorado), acreditaciones, convenios y ambientes de negocios. Para citar uno de los casos más destacados según la revista América Economía (2006), en 2005 en la ciudad de Sao Paulo se registraron 1.997 nuevas patentes industriales, mayor al volumen registrado este mismo año en Argentina, Chile y Colombia conjuntamente (1.791 en total). Entre ellas merece especial mención el Parque Tecnológico del Centro de Incubación de Empresas Tecnológicas (CIETEC) de la Universidad de Sao Paulo, cuya ciudadela albergó en 2006 a 109 compañías de los 110 espacios disponibles, donde se generan actualmente una impresionante cantidad de emprendimientos, que van desde tecnologías para grabar con láser hasta fábricas de células que producen energía a partir de hidrógeno.

\section{El factor juridico-institucional y el riesgo}

Este estratégico determinante de la competitividad urbana está referido al ambiente jurídico e institucional incorporado en forma de reglas de juego y sistemas de regulación (leyes y normativas), pero también está referido a la inestabilidad política y social, así como a la presencia de actos de corrupción, entre otros, que configuran lo que comúnmente se denomina "ambiente de riesgo empresarial”. Este indicador, aun cuando puede ser medido a nivel urbano, dadas sus características, está notoriamente influenciado por sus desempeños a nivel nacional -dada la amplia gama de regulaciones nacionales que tienen jurisdicción en los niveles regional y local. Las variables consideradas dan forma al denominado "riesgo país", indicador que es medido y publicado anualmente por un conjunto variado de calificadoras internacionales de riesgo.

Según la calificadora internacional de riesgo Standard \& Poor's, en 2007 el país latinoamericano con mejor calificación, o menor riesgo país -que es un indicador proxy del ambiente financiero- fue Chile (calificación A) seguido de México (BBB), Perú y Colombia (BB+) y Brasil (BB), que coinciden -en forma general- con el ranking de desempeños competitivos de sus centros urbanos principales. Vemos un Chile que muestra los frutos de sus pioneras y sostenidas reformas institucionales a nivel latinoamericano, un México en etapa de consolidación regional, así como los casos interesantes de Perú y Colombia, que registran las tasas de mayor crecimiento coyuntural en materia de reformas de regulación; y, finalmente, Brasil, que aunque aparece relativamente rezagado (por sus todavía altas tasas de desigualdad y marginalidad económica y social), tiene la ventaja de contar con la urbe de mayor dinamismo regional de 
la última década (Sao Paulo) y cuyo liderazgo muestra tendencias sólidas de consolidarse en el mediano y largo plazo. En contraposición, países como Bolivia y Ecuador (B-) e incluso Argentina (B) y Venezuela (B+), muestran notorios problemas de riesgo crediticio, que influyen en las decisiones de los inversores extranjeros de localizar sus empresas en estos territorios.

En forma similar, el Banco Mundial (World Bank, 2008) en su publicación anual Doing Business, muestra que en términos de la facilidad para hacer negocios los países latinoamericanos de mejor posición a nivel global (sobre una muestra de 178 países) fueron: Puerto Rico (puesto 28) seguido por Chile (33), México (44), Perú (58) y Colombia (66); en tanto que los de menores facilidades o mayor regulación fueron: Venezuela (172), Haití (148) y Bolivia (140). Sin embargo, llama la atención que de acuerdo a este indicador, incluso países como Brasil (122) y Argentina (109) mostraron tener problemas jurídicos e institucionales (regulaciones) a la hora de emprender un negocio o proyectarlo. En este sentido, el citado indicador se constituye en un catalizador del ambiente de negocios de un país y, por lo tanto, de la capacidad que tendría para fomentar actividades económicas internas y atraer inversiones extranjeras, además de servir como indicador proxy de los potenciales y limitaciones que eventualmente tendrían los sistemas de regulación de las economías nacionales, regionales y locales (urbanas).

Otra variable que influencia en el nivel riesgo y que también está directamente relacionada a los desempeños competitivos de cada país es, sin duda, el grado de corrupción política, cuyos datos para el 2007 a partir del informe de la consultora Transparencia Internacional (2008) muestran que los países con menor percepción de corrupción en América Latina-considerando 10,0 y 1,0 como los valores extremos de menor y mayor percepción de corrupción, respectivamente- fueron Chile y Uruguay (con 6,9 puntos, lo que los colocó en el puesto 23 de 180 países), seguidos por Puerto Rico (5,8 / puesto 36), Costa Rica (5,1 / puesto 47), Colombia (3,8 / puesto 70) y Perú (3,6 / puesto 72). En el lado opuesto aparecen países como Haití (1,4 / puesto 177), Venezuela (1,9 / puesto 158), Ecuador (2,0 / 151) y Paraguay (2,4 / puesto 138). No obstante, llama la atención la relativamente baja puntuación obtenida por México (3,6 / puesto 72), Brasil (3,5 / puesto 80) y Argentina (2,9 / puesto 109), que aun cuando lideran en términos de competitividad urbana, incorporan paralelamente preocupantes índices de corrupción que parecen no haber sido debidamente enfrentados durante los últimos años. De todos modos se puede identificar -con ciertas excepciones- la existencia de una relación relativamente directa entre los niveles de percepción de corrupción y los desempeños competitivos de las economías nacionales y las principales economías urbanas de Latinoamérica, lo que permite colegir que la corrupción política actúa como un factor restrictivo de la competitividad, debido a que absorbe recursos públicos que eventualmente deberían financiar el desarrollo interno; pero, además, porque restringe las posibilidades de atracción de inversión extranjera, dado que el agente extranjero lo toma como un relativamente buen indicador de la ausencia de respeto a las reglas de juego y la institucionalidad de una sociedad, que eventualmente podría afectar a sus intereses privados, sean estos individuales o corporativos.

\section{Conclusiones}

Se pueden señalar por lo menos cuatro temáticas que resaltan del análisis de la competitividad urbana -o más propiamente la competitividad metropolitana- en América Latina. 
Primeramente, la preocupante evidencia de la todavía escasez y/o visible heterogeneidad de la información sobre desempeńos comparados de las principales metrópolis latinoamericanas, tanto a nivel cuantitativo (indicadores), como a nivel metodológico (modelos de análisis). No obstante, es también justo mencionar la existencia de importantes avances en la recolección, sistematización y análisis de información, principalmente la referida al campo empresarial y de negocios y, en menor medida, al de los gobiernos locales y/o regionales, que por su especial misión institucional deberían ser los más interesados en promocionar diagnósticos, estudios y análisis en torno a la temática de la competitividad urbana.

La segunda temática está referida al proceso de medición de los niveles de competitividad metropolitana en América Latina, donde se aprecia que, independientemente de la metodología utilizada y las fuentes de información, durante el periodo 2001-2008 fueron las ciudades de Sao Paulo, Santiago, Ciudad de México y Buenos Aires las que mostraron los mayores avances en términos de posicionamiento competitivo, con tendencias que se muestran relativamente estables en el mediano y largo plazo. Al contrario, ciudades como Río de Janeiro, Caracas y Ciudad de Guatemala, presentan rasgos de retroceso asociado al aparente predominio de los impacto negativos del crecimiento urbano, fenómeno que aparece con más claridad en ciudades como Quito, pero sobre todo Asunción y La Paz, que aun cuando son mucho más pequeñas en términos demográficos, tienen economías urbanas donde se reproducen gran parte de los problemas de las grandes urbes. En un tercer grupo de ciudades, se encuentran los casos de economías urbanas -en general de tamaño mediano- que presentan también interesantes desempeños, donde resaltan las ciudades de Monterrey y Querétaro en México, así como Curitiba en Brasil; no obstante, merecen especial referencia los casos de las capitales de Perú y Colombia: Lima y Bogotá respectivamente, que mostraron los desempeños urbano-regionales latinoamericanos más dinámicos de los últimos años.

Una tercera temática que resalta es la referida a los factores determinantes de la competitividad metropolitana en América Latina, donde se observa que -aun cuando no sobresale ninguno de ellos en forma clara- merecen especial atención: a) la influencia mostrada por el avance en el uso y difusión de tecnologías de punta, principalmente aquellas asociadas al sector telecomunicaciones (conectividad digital), b) la creación de capital humano, tanto a partir de la instalación de centros educativos de excelencia como mediante canalización de la inversión hacia programas de fomento a la innovación (I\&D), principalmente en áreas de ciencia aplicada, y c) la inversión dirigida a la creación de infraestructura y equipamiento de apoyo a la producción, que permite la generación de las denominadas economías de escala. Menor influencia mostraron tener los factores geográfico-locacionales e institucionales, lo que, sin embargo, se debe a la deficiente información disponible -sin desmerecer de manera alguna su importancia, que en algunos casos adquiere un carácter estratégico-. De todos modos, las economías metropolitanas latinoamericanas que resaltan claramente en la mayoría de los citados factores determinantes de la competitividad urbana son Sao Paulo, Santiago de Chile, Buenos Aires, Ciudad de México, Bogotá y Monterrey, por citar las más importantes, cuyos comportamientos históricos -aun cuando incorporan ciertos periodos de relativa inestabilidad en sus indicadores- muestran en general una tendencia marcada hacia la consolidación en el mediano, pero sobre todo, en el largo plazo. 
Finalmente, es imprescindible mencionar la importancia que tienen los conceptos de calidad de vida y externalidades negativas urbanas en el análisis de los indicadores utilizados para medir niveles y factores determinantes de competitividad urbana en América Latina. Aun cuando -como se explicó anteriormente- tienen evidentes limitaciones de carácter metodológico, permiten avanzar en la tarea de identificar ciertas particularidades pasadas muchas veces por alto o subvaluadas en los procesos tradicionales de confección de los ranking de ciudades. En este marco, ciudades como Buenos Aires y Montevideo, y en menor medida San Juan y Monterrey, serían las eventuales ganadoras o beneficiarias - pese a sus relativamente bajos desempeńos económicos coyunturales-, en tanto que otras como Ciudad de México, Sao Paulo y en menor medida Santiago de Chile, serían las eventuales perdedoras o perjudicadas, aun cuando registren los mejores desempeños económicos al interior de la mayoría de los modelos actuales de análisis de competitividad urbana. Por lo mismo, estos modelos deberían ser permanentemente ajustados (mejorados), con la esperanza de que puedan servir como fuente de información cada vez más confiable para las complementarias futuras investigaciones que se requieren desarrollar sobre el tema.

\section{Referencias bibliográficas}

América Economía (2006). Bienvenidos a la selva: todos contra todos en Sudamérica, Revista América Economía, No 324, mayo.

América Economía (2007). Las mejores ciudades para hacer negocios en América Latina, Revista América Economía, No 341, mayo.

América Economía (2008a). Las mejores ciudades para hacer negocios en América Latina, Revista América Economía, No 357, abril.

América Economía (2008b). 500 mayores empresas de América Latina, Revista América Economía, No 361, julio.

Begg, I. (1999). Cities and competitiveness. Urban Studies, Vol. 36, num. 5-6, 795-809.

Cabrero, E., Orihuela, I. \& Ziccardi, A. (2003). Ciudades competitivas-ciudades cooperativas: conceptos clave y construcción de un índice para ciudades mexicanas, Documento de Trabajo 139, México: División de Administración Pública, CIDE.

Cabrero, E., Orihuela, I. \& Ziccardi, A. (2007). Competitividad de las ciudades mexicanas 2007: La nueva agenda de los municipios urbanos, México: CIDE.

Cárcamo-Díaz, R. (2004). Towards development in landlocked economies. Serie Macroeconomía del Desarrollo, No 29. CEPAL.

CEPAL (2003a). Estudio preliminar del transporte de los productos de comercio exterior de los paises sin litoral de Sudamérica. Documento de Referencia, Reunión Regional de Países sin Litoral Marítimo. CEPAL.

CEPAL (2003b). Panorama Social de América Latina 2002-2003. CEPAL.

CEPAL (2005). América Latina: Proyecciones de población urbana y rural 1970-2025. Boletín Demográfico $N^{\circ}$ 7. CELADE.

CEPAL (2006). Panorama Social de América Latina 2006. Informes periódicos institucionales. CEPAL.

CEPAL (2008). La inversión extranjera en América Latina y el Caribe, 2007. Serie Anual de la División de Desarrollo Productivo y Empresarial. CEPAL. 
Cho, D. S. (2006). The study of urban competitiveness in Korea: A dynamic approach to city competitiveness, en Kresl y Pengfei (Eds.). Global Urban Competitiveness Report (198207). Social Sciences Academic Press.

Deas, I. \& Giordano, B. (2001). Conceptualizing and measuring urban competitiveness in major English cities: An exploratory approach. Environment and Planning, Vol. 13, 1411-1429.

Galetovic, A. (2006) (Editor). Santiago. Dónde estamos y hacia dónde vamos. Santiago de Chile: Centro de Estudios Públicos (CEP).

Galindo, L., Escalante, R. \& Asuad, N. (2004). El proceso de urbanización y el crecimiento económico en México. Estudios Demográficos y Urbanos, Vol. 19, No 2 (56), pp. 289312.

Gallup, J. (2000). Geography and Socioeconomic Development: Background paper examining the state of the Andean region. Washington: Andean Competitiveness Project.

Gallup, J., Mellinger, D. \& Sachs, J. (1998). Geography and economic development. National Bureau of Economic Research, Working Paper No. 6849.

Garza, G. (2006). Productividad laboral del sector terciario en la Ciudad de México, 19602003. Investigaciones Regionales, Vol. 8, 55-84.

Gómez, M. \& Sabeh, E. (2001). Calidad de vida. Evolución del concepto y su influencia en la investigación y la práctica. Salamanca: Instituto Universitario de Integración en la Comunidad, Facultad de Psicología, Universidad de Salamanca.

Hausmann, R. (2001). Prisoners of Geography. Foreign Policy, No. 122, 44-62.

Kresl, P. (1995). The determinants of urban competitiveness, en Kresl and Gappert (Eds.), North American Cities and the Global Economy: Challenge and Opportunity (45-68). Sage Publications.

Kresl, P. \& B. Singh (1999). Competitiveness and the urban economy: Twenty four large US metropolitan areas. Urban Studies, No 36, (5-6), 1017-1027.

Kresl, P. \& N. Pengfei (2006) (Eds.). Global Urban Competitiviness Report: 2006. China: Social Sciences Academic Press.

Leva, G. (2005). Indicadores de calidad de vida urbana: Teoría y metodología. Quilmes: Hábitat Metrópolis, Universidad Nacional de Quilmes.

Lever, W. \& Turok, I. (1999). Competitive cities: Introduction to the review. Urban Studies, Vol. 5-6, 791-793.

Martin Simon, J. L. (2003). Economías de escala, economías externas e integración económica. Cuadernos de Estudios Empresariales, No 13, pp. 203-214.

Mercer Human Resources and Investment Consulting (2008). Quality of living: 2008. Washington D.C.: Mercer.

Mulder, N. (2006). Aprovechar el auge exportador de productos básicos evitando la enfermedad holandesa. Serie Comercio Exterior, No 80. CEPAL.

Pengfei, N., Jianfa, S. \& Haibo, J. (2006). The study of urban competitiveness in China, en P. Kresl y N. Pengfei (Eds.), Global Urban Competitiveness Report: 2006 (208-249). China: Social Science Academic Press.

Porter, M. (1991). La ventaja competitiva de las naciones, Buenos Aires: Vergara.

Sachs, J. \& Wagner, A. (1997). Natural resources abundance and economic growth, Boston: Center for International Development-Harvard University.

Samuelson, P. \& Nordhaus, W. (1999). Economía. Madrid: McGraw Hill. 
Sobrino, J. (2003). Competitividad de las ciudades de México. México: El Colegio de México.

Sobrino, J. (2006). "Competitividad y empleo en las principales metrópolis de México", en J. Lezama y J. Morelos (Eds.), Población, Ciudad y Medio Ambiente en el México Contemporáneo. México: El Colegio de México.

Transparencia Internacional (2008). Índice de Percepción de la Corrupción 2008. Transparency Internacional: The global coalition against corruption.

Turok, I. (2004). "Cities, regions and competitiveness". Regional Studies, Vol. 38.9, 10691083.

World Bank (2008). Doing Business 2008. Washington: World Bank.

World Economic Forum (2006). Global Competitiveness Report 2006-2007. Geneve: Center for International Development. 